\title{
BULANIK HEDEF PROGRAMLAMA İLE MENÜ PLANLAMA
}

\section{Yrd. Doç. Dr. Kenan Oğuzhan ORUÇ*}

\section{ÖZ}

İsyeri, okul, hastane vb. kurumlardaki kişilerin beslenme ihtiyacının karşılanması olarak tanımlanan toplu beslenmenin önemli aşamalarından birisi de menü planlamasıdır.Menü planlama; maliyet, enerji/besin ögesi ihtiyacı, tat, çeşitlilik vb. birçok etmenin dikkate alınması ve eş zamanlı gerçekleştirilmesi gereken birden fazla amacın olduğu, karmaşık bir süreçtir. Bu sürecin planlanmasında çok amaçlı bir karar verme tekniği olan hedef programlama, kullanılabilecek yöntemlerden birisidir. Veri tabanlı bir teknik olan hedef programlamada, kullanılan verilerin kesin olmadığı durumlar için bulanık hedef programlama modelleri geliştirilmiştir.Bu çalışmada; 19-30 yaş arası işçiler için,set-seçimsiz, 20 günlük öğle yemeği menü planlaması yapılmıştır. Planlama sürecinde, verilerdeki bulanıklıklar da dikkate alınarak bulanık hedef programlama yöntemi kullanılmıştır.

Anahtar Kelimeler: Menü Planlama, Beslenme, Bulanı, Hedef Programlama.

JEL Sinıflandırması: C44, C61, L66.

\section{MENU PLANNING WITH FUZZY GOAL PROGRAMMING}

\begin{abstract}
Defined as the fulfillment of nutritional requirements of people working at different places such as schools, hospitals etc., public food service's one of the most important stage is menu planning.Menu planning is such a complex process that one should take not only many factors into consideration like cost, energy/nutrition units, taste, diversity etc., but also some aims which should be practiced simultaneously. One of the programs which can be used in programming for such a process is goal programming, a technic for multi-purpose decisions. In the goal programming as a data based technic, fuzzy goal programming models have also been advanced for the situations in which data are not certain.In this study, an example lunch meal menu planning is prepared for the workers between 19 and 30 years old. The menu is planned as non-optional. During the process of planning, fuzzy goal programming method was used in consequence of fuzziness in data.
\end{abstract}

Keywords: Menu Planning, Nutrition, Fuzzy, Goal Programming.

Jel Classification:C44, C61, L66.

Süleyman Demirel Üniversitesi, İ̈BF Ekonometri Bölümü, kenanoruc@sdu.edu.tr 


\section{GíRIŞ}

Bireyin yaşamını sürdürebilmesi ve sağlığını koruyabilmesi için çeşitli besinleri kullanması beslenme; yaş, cinsiyet ve fiziksel aktivite durumlarına göre gereksinim duyduğu enerji ve besin ögelerinin yeterince alınması ise yeterli beslenmeolarak tanımlanmaktadır (Eraslan,Gülegül, Sunar, Uygur, Panal, ve Konakoğlu, 2003:1). İnsanın hayatını sağlıklı bir şekilde devam ettirebilmesi, her şeyden önce yeterli ve dengeli beslenmesine bağlıdır (Demirci, 2003:1).

Günümüz dünyasında; çalışan erkek ve kadın sayısındaki artışa paralel olarak ev dışında yemek yiyenlerin sayısı önemli ölçüde artmakta, yemek servis endüstrisi de hızla gelişmektedir (Tümer, 2008:1).Bugün ileri sanayi ülkelerinde nüfusun \%70’inden fazlasının en az bir ögünü dışarıda tükettiği görülmektedir (Kırılmaz, 2008: 1).

Ev dışında ve çok sayıda kişiye çalıştıkları, yaşadıkları veya kaldıkları yerlerde, dışarıya çıkmadan yiyecek ve içecek ihtiyaçlarının istenen şekilde hazırlanmasıve sunulması olarak tanımlanan toplu beslenme (Eraslan vd., 2003: 2); menünün hazırlanması, besinin satın alınması, pişirilmesi, çöp ve atıkların kaldırılması, personel yönetimi vb. birçok aşamanın planlanmasını gerektiren bir sistemdir (Kırılmaz, 2008: 4-5).Bu sistem içinde menü planlama; maliyet, enerji ve besin ögesi ihtiyacı, tat, çeşitlilik vb. birçok etmenin dikkate alınmasını gerektiren karmaşık bir süreçtir.

Literatürde, diyet ve menü planlama için önerilmiş birçok matematiksel model bulunmaktadır. Soden ve Fletcer (1992), Sklan ve Dariel (1993), Şenol (2011) karma tamsayılı doğrusal programlama, Balintfy,Ross, Sinha ve Zoltners (1978) doğrusal olmayan programlama ve dal-sınır algoritması, Ediz ve Yağdıran (2009) hedef programlama,Günyaşar ve Oral (2005) çok amaçlı doğrusal programlama ve baskın çözüm yöntemlerini kullanarak model önerisinde bulunmuştur. Önerilen bu modellerde veriler net/kesin değeri bilinen veriler olarak alınmıştır. Fakatmenü planlanma için gerekli olan kesin/net verilere ulaşmak genelde mümkün olmamaktadır. Verilerin kesin olmadığı, bulanıklık içerdiği durumlarda Zadeh (1965) tarafindan geliştirilen bulanık küme teorisi temel alınarak bulanık modelleme yapılmaktadır.

Mamat,Rokhayati, Noor, ve Mohd (2011) gıda fiyatlarının, Mamat,Zulkifli, Deraman, ve Noor (2012) gıdadaki karbonhidrat miktarı ile yağlı besinlerin, Oruç,Güngör, Irmak, ve Şenol (2012) besin ögesi ve enerji miktarı/ihtiyaçları ile fiyatların bulanık sayı olarak alındığı, planlamanın bulanık doğrusal programlama ile yapıldığı modeller önermişlerdir. Bu çalışmalarda amaç fonksiyonu ya maliyetin ya da alınan bazı besin ögesi miktarlarının minimizasyonu şeklindedir.Fakat menü planlama sürecinde hem maliyetin minimize edilmesi, hem de enerji ve besin ögelerinin yeterince alınmas1 amaçlanmaktadır.Planlamanın doğrusal programlama modeli kullanılarak yapılması; bu hedeflerden sadece birinin amaç fonksiyonunda, diğerlerinin ise kısıtlarda yer alması zorunluluğunu getirmektedir. Örneğin maliyet minimizasyonu amaç fonksiyonlu bir planlamada, alınması gereken besin ögesi ve enerji miktarlarının ortalamaları kısıtların alt sınırlarını oluşturduğu için modelin yapısı gereği 
alınması gerekenin hep üzerinde besin ögesi ve enerji alınmaktadır. Ancak, doğru bir menü planlama için hem maliyetten hem de alınması gereken enerji ve besin ögesi miktarlarından sapmalarınminimize edilmesi gerekmektedir. Bu anlamda menü planlama problemlerinin, verilerdeki bulanıklığın da dikkate alınarak çok amaçlı karar problemi olarak modellenmesinin daha doğru olacağı düşünülmektedir. Birden fazla amacın bulunduğu karar problemlerinin çözümünde kullanılabilecek yöntemlerden birisi de hedef programlamadır.

$\mathrm{Bu}$ çalışmada orta aktiviteli işlerde çalışan 19-30 yaş arası işçiler için; set-seçimsiz, 3 veya 4 kaplı öğle yemeği menü planlanması yapılmıştır.Planlama haftanın 5 günü yemek verilen işletmeler için yapılarak, 1 ay için 20 günlük menüler oluşturulmuştur. Planlama sürecinde verilerdeki bulanıklıklar da dikkate alınarak bulanık hedef programlama yöntemi kullanılmıştır.Modelde; 1280 karar değişkeni, 162 sapma değişkeni, 81 hedef, 488 kısıt kullanılmıştır. Kurulan modelin çözümüGAMS 22.5 paket programı ile yapılmıştır.

\section{BULANIK HEDEF PROGRAMLAMA}

Çok amaçlı karar problemlerinde birden fazla amaç olduğu ve bu amaçlar genellikle birbiriyle çeliştiği için hepsinin eş zamanlı olarak optimize edilmesi neredeyse imkânsızdır. Bu tür problemlerin çözümündekullanılabilecek bir yöntem olan hedef programlama, her amacın önem derecesi temel alınarakoptimum çözümdençokuzlaşık çözüm bulunmasınısağlayan matematiksel bir yöntemdir (Taha, 2009: 343).

Hedef programlamada ilk olarak işletmenin amaçları, bu amaçlar için sayısal hedefler ve bu hedefler arasındaki önem sırası belirlenir. Daha sonra önem sırasınagöre hedeflere ağırlık verilir. Ağırlıklandırma,kodlar (öncelikli hedef programlama) veya sayısal değerler (ağırlıklı hedef programlama) kullanılarak yapılır. Ağırlıklandırmayla daha önemli hedeflerin daha önce doyurulması sağlanır. Amaç fonksiyonu ise kısıtlara bağlı olarak ağırlıklandırılmış hedeflerden sapmaların minimizasyonu şeklindedir. (Öztürk, 2009: 274).Tüm parametreleri bulanık olan öncelikli bir hedef programlama modeli aşağıdaki gibi ifade edilebilir:

Amaç Fonksiyonu:

$$
\mathrm{Z}_{\min }=\sum_{\mathrm{k}=1}^{1} \sum_{\mathrm{i}=1}^{\mathrm{m}} \mathrm{P}_{\mathrm{k}}\left(\mathrm{d}_{\mathrm{i}}^{+}+\mathrm{d}_{\mathrm{i}}^{-}\right)
$$

Kisitlar:

$$
\begin{array}{lll}
\sum_{\mathrm{j}=1}^{\mathrm{n}} \tilde{\mathrm{a}}_{\mathrm{ij}} \mathrm{x}_{\mathrm{j}}-\mathrm{d}_{\mathrm{i}}^{+}+\mathrm{d}_{\mathrm{i}}^{-}=\tilde{\mathrm{b}}_{\mathrm{i}} \quad \mathrm{i}=1,2, \ldots ., \mathrm{m} & \text { (Hedefler) } \\
\sum_{\mathrm{j}=1}^{\mathrm{n}} \tilde{\mathrm{a}}_{\mathrm{tj}} \mathrm{x}_{\mathrm{j}}(\geq, \leq,=) \tilde{\mathrm{b}}_{\mathrm{t}} \quad \mathrm{t}=1,2, \ldots, \mathrm{v} & \text { (Model Kisitlari) } \\
\mathrm{P}_{1}>\mathrm{P}_{2} \ldots \ldots . \mathrm{P}_{\mathrm{k}} \quad \mathrm{k}=1,2, \ldots, 1 & \\
\mathrm{x}_{\mathrm{j}}, \mathrm{d}_{\mathrm{i}}^{+}, \mathrm{d}_{\mathrm{i}}^{-} \geq 0 \quad \mathrm{i}=1,2, \ldots, \mathrm{m} \quad \mathrm{j}=1,2, \ldots, \mathrm{n} &
\end{array}
$$

Burada, 
$\mathrm{P}_{\mathrm{k}}: \mathrm{k}$. hedefin öncelik sıras1

$\mathrm{d}_{\mathrm{i}}^{+}:$i. hedeften pozitif sapma miktarı

$\mathrm{d}_{\mathrm{i}}^{-}:$i. hedeften negatif sapma miktarı

$\mathrm{x}_{\mathrm{j}}: \mathrm{j}$. karar değişkeni

$\tilde{a}_{\mathrm{ij}}: \mathrm{j}$. karar değişkeninin i. hedefe katkısı (kullanım miktarı)

$\tilde{b}_{i}:$ i. bulanık hedef düzeyi

$\tilde{\mathrm{a}}_{\mathrm{ij}}: \mathrm{j}$. karar değişkeninint. üretime katkısı (kaynağı kullanım miktarı)

$\tilde{\mathrm{b}}_{\mathrm{t}}$ : t. bulanık kaynak (üretim) miktarı

Bulanık küme teorisine göre her bulanık sayı bulanık bir kümedir ve bulanık kümelerde kümenin elemanları $[0,1]$ arasında değişen üyelik dereceleri $(\mu)$ alarak o kümeye dâhil olur. Eğer küme elemanı; 1 üyelik derecesi alıyorsa kümenin tam elemanıyken, 0 üyelik derecesi alıyorsa kümenin elemanı değildir (Abdel Kader ve Dugdale, 2001:457). Üyelik fonksiyonu problemin durumuna göre birçok biçimde tanımlanabilir. Bu çalışmada kullanılan,alt ve üst sınır değerleri bilinen, doğrusal artan ve azalan üyelik fonksiyonlu $\tilde{x}=\left(x^{L}, x^{U}\right)$ bulanık sayısı:

\section{Grafik1.Artan Üyelik Fonksiyonu}

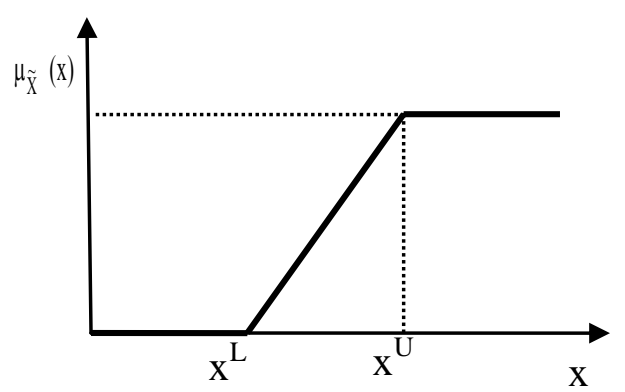

$$
\mathrm{x}=\mathrm{x}^{\mathrm{L}}+\left(\mathrm{x}^{\mathrm{U}}-\mathrm{x}^{\mathrm{L}}\right) \mu
$$

\section{Grafik 2.Azalan Üyelik Fonksiyonu}

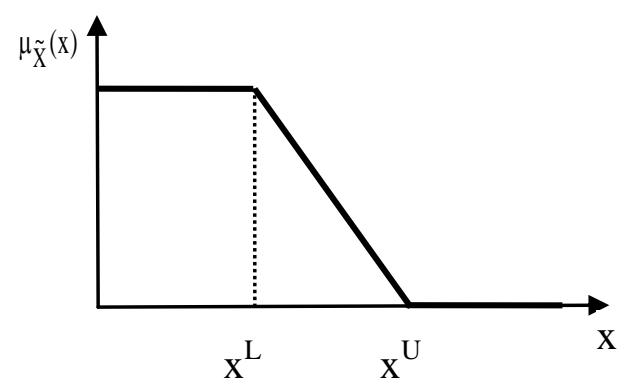

$$
\mathrm{x}=\mathrm{x}^{\mathrm{U}}-\left(\mathrm{x}^{\mathrm{U}}-\mathrm{x}^{\mathrm{L}}\right) \mu
$$

şeklindetanımlanabilir (Baykal, 2004:78-80). ( $\mu$ ) üyelik derecesine göre hesaplanan (x),kesin değeri bilinen bir sayıdır. $(\mu) ;(\mathrm{x})$ elemanının $(\tilde{\mathrm{x}})$ bulanık kümesine ait olma derecesini ifade etmektedir. 
Literatürdeki bulanık hedef programlama modellerinde sadece hedefler bulanık olarak tanımlanmakta, modelin çözümü sonucu hesaplanan üyelik dereceleriise ilgili hedefin gerçekleşme derecesiniifade etmektedir. Literatürdeki bu çalışmalar hedeflerin öncelik yapısına göre; bütün hedeflerin eşit öncelikli olduğueş ağırlıklı bulanık hedef programlama modelleri ve hedeflerin farklı önceliklere sahip olduğuöncelikli bulanık hedef programlama modelleri olmak üzere iki temel başlık atında sınıflandırılabilir (Özkan, 2003: 181).

Bulanık hedef programlama problemlerinin çözümü için Narasimhan (1980), Hannan (1981) ile Yang vd. (1991) tarafından önerilen modeller hedefler arasında tercih önceliği olmayan bulanık hedef programlama problemlerinin çözümünde kullanılabilecek modellerdendir. Tiwari,Dharmar, ve Rao(1986), Chen (1994) ile Kim ve Whang (1998) ise hedeflerin farklı önceliklerinin olduğu bulanık hedef programlama problemlerininçözümünde kullanılabilecek modeller önermişlerdir. Önerilen bu modeller, bulanık hedeflerin üçgen üyelik fonksiyonuna sahip olduğu karar problemleri içindir.Ayrıca Wang ve Fu (1997), karar vericilerin risk gruplarına göre sınıflandırıldığı ve bu sınıflandırmaya göre üyelik fonksiyonu tanımlamasının yapıldığı bulanık hedef programlama modeli önermiştir(Özkan, 2003: 183-228).

Daha önce değinildiği gibi bulanık hedef programlama problemleri için önerilen modellerin tamamında sadece hedefler bulanık olarak alınmıştır. Fakat menü planlama problemlerinde tüm parametreler bulanıktır. Bu parametrelerin bulanık olma gerekçeleri sonraki bölümde ayrıntılı olarak açıklanmıştır.

Bu çalışmada; tüm parametreleri bulanık olan problemler için Carlsson ve Korhonen (1986) tarafından önerilmiş olan bulanık doğrusal programlama modeli temel alınarak,hedef programlama modeline dönüştürülmüştür. Carlsson ve Korhonen (1986) bulanık parametrelerin alt ve üst sınır değerlerinin bilinmesi (yani $\tilde{\mathrm{a}}=\left(\mathrm{a}^{\mathrm{L}}, \mathrm{a}^{\mathrm{U}}\right), \tilde{\mathrm{b}}=\left(\mathrm{b}^{\mathrm{L}}, \mathrm{b}^{\mathrm{U}}\right)$ ) durumunda, bulanık sayının uygulanabilir (gerçekleştirilebilir) değerinden (yani $\mu=1$ ), uygulanması mümkün olmayan (gerçekleştirilmesi olanaksız) değerine (yani $\mu=0$ ) doğru, çeşitli üyelik fonksiyonları için çözülebilen model önermiştir. Model; doğrusal, parçalı doğrusal, üstel, hiperbolik vb. olmak üzere pek çok üyelik fonksiyonu için uygulanabilmektedir.Modelin en önemli aşaması bulanık parametrelerin üyelik fonksiyonlarının oluşturulması aşamasıdır. Üyelik fonksiyonu; $\mu=1$ için bulanık sayının uygulanabilir sınır değerini, $\mu=0$ için ise uygulanması olanaksız sınır değerini alacak şekilde oluşturulmalıdır. Daha sonra tanımlanan bu üyelik fonksiyonlarına göre karar vericinin tercih ettiği $(\mu)$ değeri/değerleri için,model bulanıklıktan kurtarılarak çözülür. Elde edilen sonuç, çözümün yapıldığı $(\mu)$ üyelik derecesinde bu sonucungerçekleştirilebileceği şeklinde yorumlanabilir. 


\section{TOPLU BESLENME SİSTEMLERINNDE MENÜ PLANLAMA}

$\mathrm{Bu}$ çalışmada menü planlamanın yapıldığı orta aktiviteli, 19-30 yaş arası işçilerin öğle yemeğinde alması gereken ortalama enerji ve bazı besin ögesi miktarlarından bazıları tablo 1'de verilmiştir.

Tablo 1.Orta Aktiviteli, 19-30 Yaş Arası İşçilerin Ekmek Haricinde Öğle Yemeğinde Alması Gereken Ortalama Enerji ve Bazı Besin ÖgesiMiktarları

\begin{tabular}{|c|c|c|}
\hline Enerji - Besin Ögesi & Parametre İçin Kullanılan Simge & Ortalama Miktar \\
\hline Enerji (kkal) & E & 750 \\
\hline Protein $(\mathrm{g})$ & $\mathrm{P}$ & 22,7 \\
\hline Tiamin $(\mathrm{mg})$ & $\mathrm{T}$ & 0,38 \\
\hline C vitamini $(\mathrm{mg})$ & $\mathrm{CV}$ & 34 \\
\hline
\end{tabular}

Kaynak:Oruç vd., 2012: 10;Ediz ve Yağdıran, 2009:73.

Genellikle çalışan personele hizmet veren toplu beslenme sistemlerinde,yemek seçim şansı tanınmayan set-seçimsiz menüler kullanılmaktadır. Bu menülerde yer alan yemek sayısı 3-4 kapla sınırlandırılır (Ediz ve Yağdıran, 2009: 48, Beyhan ve Ciğerim, 1995: 10-32). Set-seçimsiz menüler oluşturulurken bir menü iskeleti oluşturulur. İskelet oluşturma aşamasında yemek grupları temel alınarak, her gruptan genellikle bir adet yemek alınır. Başlıca yemek grupları şunlardır (Ediz ve Yağdıran, 2009: 49, Beyhan ve Ciğerim, 1995: 23-40):

Birinci grup yemekler $(B G)$ : Büyük ve küçük parça et yemekleri, köfteler, balık, etli sebze yemekleri, etli dolma ve sarmalar, etli kurubaklagiller.

$\checkmark$ İkinci grup yemekler $(\dot{I} G)$ : Çorbalar, pilavlar, makarnalar, börekler, zeytinyağl1 yemekler.

$\checkmark$ Üçüncü grup yemekler( $\ddot{U} G)$ : Meyveler, salatalar, tatlılar, kompostolar, hoşaflar ve diğerleri.

Bu çalışmada 22 adet birinci, 18 adet ikinci, 24 adet üçüncü grup olmak üzere toplam 64 adet yemek için menü planlaması yapılmıştır. Yemek isimleri, yemeklere verilen kodlar, 1 porsiyon yemeğin enerji ve besin ögesi değerleri ile maliyetleri tablo 2'de verilmiştir. Model aşağıdaki standartlar esas alınarak kurulmuştur:

$\checkmark$ Amaç Fonksiyonu:1 kişinin 20 gün için, yemek maliyeti hedefinden pozitif sapma ile enerji ve besin ögesi ihtiyacı hedeflerinden sapmaların toplamının minimizasyonu şeklinde tanımlanmıştır. Hedefler arasında önceliklendirme yapılmamıştır.[1]

$\checkmark$ Bir Porsiyon Yemek Kavramındaki Bulanıklık:Bir porsiyon yemek kavramı; verilen yemeğin miktarı, porsiyonda bulunan malzemelerin oranı vb. bağlamında göreceli bir kavramdır. Çünkü bir işçiye verilen porsiyondaki et, su, soğan, patates vb. miktarı/oranı ile diğer işçiye verilen porsiyondaki miktar aynı olmayacaktır.

$\checkmark$ Yemek Maliyetlerindeki $\left(C_{i}\right)$ Bulanıklık: Her yemeğin maliyeti porsiyon olarak bellidir (tablo2). Fakat bir porsiyon yemek kavramı yukarıda açıklanan sebeplerden dolayı bulanık bir kavramdır.

Parantez içindeki rakamlar hedef/kısıt numaralarını göstermektedir 
Ayrıca yemek yapımında kullanılan malzemelerin fiyatları alındığı mevsim, piyasa koşulları vb. bağlamında farklılık gösterebilmekte,kimi zaman çürük, bozuk malzemeler de olmaktadır. Fakat her yemeğin maliyetini bu tür etkenleri tam yansıtarak hesaplamak uygulanabilir değildir. $\mathrm{Bu}$ sebeplerden dolayıyemek maliyetleri sağdan ve soldan $\% 5$ bulanıklaştırılmıştır. Ayrıca kalite ve damak tadı standardını korumak şartıyla, bir yemeğin maliyetinin düşürülmesinin uygulanabilirliği, maliyet fiyatı düştükçe azalacaktır. Çünkü iyibir yemek daha iyi malzeme kullanılarak daha kolay yapılabilir (uygulanabilir).Örneğin iyi bir rosto, etin kaliteli kısmından daha kolay yapılabilir. Kaliteli malzemenin genellikle daha maliyetli olduğu bir gerçektir. Bu da standartlara uygun yemeğin uygulanabilirlik anlamında yüksek fiyata alınan(kaliteli) malzeme kullanılarak daha kolay yapılabileceği sonucunu doğurmaktadır.Bu durumda yemek fiyatı arttıkça, üyelik derecesi de artacaktır. Bu sebeple bulanıklaştııılan bu sayınınartan üyelik fonksiyonuna sahip olduğu söylenebilir.Bulanık yemek maliyetleri ile üyelik fonksiyonları $\mathrm{C}=\mathrm{C}^{\mathrm{L}}+\left(\mathrm{C}^{\mathrm{U}}-\mathrm{C}^{\mathrm{L}}\right) \mu$ formülü ile hesaplanarak tablo 3’te verilmiştir.

$\checkmark 1$ Kişi İçin 20 Günlük Toplam Yemek Maliyeti Hedefi: Yemek maliyetlerindeki benzer sebeplerden dolayı,toplam maliyet hedefi de artan üyelik fonksiyonlu bulanık sayı olacaktır. Bu çalışmada maliyet hedefi (27,34 TL; 32,38 TL) alt ve üst sınır değerli bulanık sayı olarak alınmıştır. $\mathrm{Bu}$ maliyet rakamları, aynı verilerin kullanıldığı ve minimum maliyet amaç fonksiyonlu bulanık doğrusal programlama modeli olarak kurulup çözülen Oruç vd.'nin (2012) çalışmasında elde edilen minimum ve maksimum maliyet rakamlarıdır.Maliyet hedefi bulanık verisinin üyelik fonksiyonu,

\section{Grafik 3.Toplam Yemek Maliyeti Hedefi Üyelik Fonksiyonu}

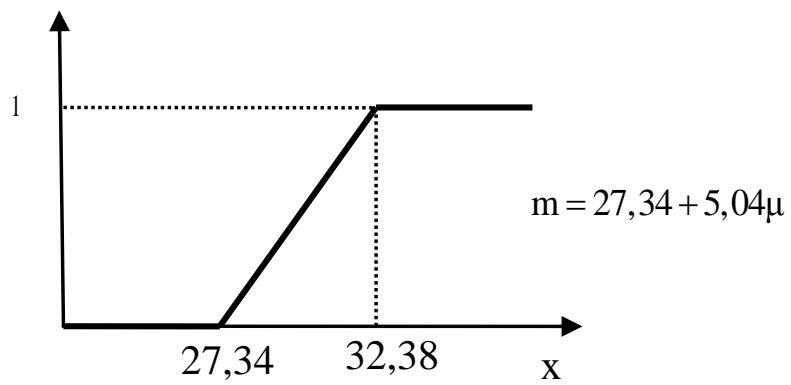

şeklinde hesaplanabilir.[2]

Yemeklerin Enerji ve Besin Ögesi Değerleri: Bir porsiyon kavramındaki bulanıklıktan dolayı her porsiyonda bulunan enerji ve besin ögesi miktarı da değişik olacaktır. Bu yüzden yemeklerin enerji ve besin değerleri sağdan ve soldan \%5 bulanıklaştırılmıştır. Yemeklerin enerji ve besin ögesi değerlerinin artırılmasının uygulanabilirliği, enerji ve besin ögesi değeri arttıkça azalacaktır. Örneğin yemeğin biraz daha pişirilmesi besin ögesinin ve enerjinin azalmasına sebep olmaktadır. Sonuç olarak bir yemeğin enerji ve besin ögesi değeri arttıkça, üyelik derecesi azalacaktır. Bu sebeple bulanıklaştırılan bu sayının azalan üyelik fonksiyonuna sahip olduğu söylenebilir.Bulanık enerji ve besin ögesi değerleri ile üyelik fonksiyonları 
$\mathrm{E}=\mathrm{E}^{\mathrm{U}}+\left(\mathrm{E}^{\mathrm{U}}-\mathrm{E}^{\mathrm{L}}\right) \mu, \quad \mathrm{P}=\mathrm{P}^{\mathrm{U}}+\left(\mathrm{P}^{\mathrm{U}}-\mathrm{P}^{\mathrm{L}}\right) \mu, \quad \mathrm{T}=\mathrm{T}^{\mathrm{U}}+\left(\mathrm{T}^{\mathrm{U}}-\mathrm{T}^{\mathrm{L}}\right) \mu, \quad \mathrm{CV}=\mathrm{CV}^{\mathrm{U}}+\left(\mathrm{CV}^{\mathrm{U}}-\mathrm{CV}^{\mathrm{L}}\right) \mu \quad$ formülleri ile hesaplanarak tablo 3 'te verilmiştir.

$\checkmark$ Enerji ve Besin Ögesi ÍhtiyacıHedefleri: Tablo 1'deki değerler ortalama ve ekmek hariç değerlerdir. Fakat gerçek hayattaki enerji ve besin ihtiyaçları; cinsiyet, yaş, fiziki özellikler, yapılan iş vb. etmenlere göre her işçi için değişmektedir. Ayrıca her bir işçinin yediği ekmek miktarı farklı olacağından ekmekten alınan enerji ve besin ögesi miktarları da farklı olacaktır. $\mathrm{Bu}$ sebeple besin ögesi ihtiyacı değerleri de sağdan ve soldan \%5 bulanıklaştırılarak, artan üyelik fonksiyonlu olarak modelde kullanılmıştır. [3-4-5-6]

Yemek Sayısı: Her bir menüde bir adet birinci, bir adet üçüncü, bir veya 2 adetikinci gruptan olmak üzere üç veya dört çeşit yemek verilir. [7-8-9]

$\checkmark$ Menü Çeşitliliği:Heryemek toplamda (20 günde); birinci ve üçüncü grup yemekler en fazla 1, ikinci grup yemekler en az 1 en fazla 3 kez verilmelidir. [10-11-12] Ayrıca herhangi bir günde verilen bir yemek tekrar en erken 5 gün sonra verilmelidir. [13-14-15]

Yemek gruplarının iskeleti oluşturulurken yemek sayısı, menü çeşitliliği ile enerji ve besin ögesi ihtiyaçlarının yanında bazı kurallara dikkat edilir. Bu kurallar şu şekilde sıralanabilir: (Ediz ve Yağdıran, 2009: 49, 52-55)

$\checkmark$ Zeytinyağlı sebze yemeklerinin yanına etli sebze yemekleri verilmemelidir. [16]

$\checkmark$ Pilavların yanına dolmalar verilmemelidir. [17]

Etli kurubaklagillerin yanında pilav çeşitleri tercih edilmelidir. [18]

$\checkmark$ Pilav, makarna ve böreklerin yanına tatlı verilmemelidir. [19]

Zeytinyağlı sebze yemeklerinin yanına salata verilmemelidir. [20]

Etli sebze yemeklerinin yanına salata verilmemelidir. [21]

Çorbaların yanına ayran verilmemelidir. [22]

İçinde patates bulunan yemekler bir arada verilmemelidir. [23]

$\checkmark$ İçinde yoğurt bulunan yemekler bir arada verilmemelidir. [24]

$\checkmark$ İçinde pirinç bulunan yemekler bir arada verilmemelidir. [25]

$\checkmark$ İçinde havuç bulunan yemekler bir arada verilmemelidir. [26]

$\checkmark$ İçinde fasulye ve kabak bulunan yemekler bir arada verilmemelidir.[27]

\section{MODELIN KURULMASI}

Karar Değişkenleri:

$$
\begin{aligned}
& B_{i j}=\left\{\begin{array}{ll}
1 & \text { i.yemek j. günde verilecekse } \\
0 & \text { i.yemek j. günde verilmeyecekse }
\end{array} \quad \mathrm{i}=1,2, \ldots ., 22 \quad \mathrm{j}=1,2, \ldots ., 20\right. \\
& \dot{\mathrm{I}}_{\mathrm{ij}}=\left\{\begin{array}{ll}
1 & \text { i.yemek j. günde verilecekse } \\
0 & \text { i.yemek j. günde verilmeyecekse }
\end{array} \quad \mathrm{i}=1,2, \ldots ., 18 \quad \mathrm{j}=1,2, \ldots ., 20\right.
\end{aligned}
$$




$$
\ddot{U}_{i j}=\left\{\begin{array}{ll}
1 & \text { i.yemek j. günde verilecekse } \\
0 & \text { i.yemek j. günde verilmeyecekse }
\end{array} \quad \mathrm{i}=1,2, \ldots ., 24 \quad \mathrm{j}=1,2, \ldots ., 20\right.
$$

\section{Sapma Değişkenleri:}

$$
\begin{array}{ll}
\mathrm{m}^{-}=20 \text { günlük toplam maliyet hedefinden negatif sapma } & \\
\mathrm{m}^{+}=20 \text { günlük toplam maliyet hedefinden pozitif sapma } & \mathrm{j}=1,2, \ldots ., 20 \\
\mathrm{e}_{\mathrm{j}}^{-}=\mathrm{j} \text {. günde alınan enerji miktarı hedefinden negatif sapma } & \mathrm{j}=1,2, \ldots, 20 \\
\mathrm{e}_{\mathrm{j}}^{+}=\mathrm{j} \text {. günde alınan enerji miktarı hedefinden pozitif sapma } & \mathrm{j}=1,2, \ldots, 20 \\
\mathrm{p}_{\mathrm{j}}^{-}=\mathrm{j} \text {. günde alınan protein miktarı hedefinden negatif sapma } & \mathrm{j}=1,2, \ldots, 20 \\
\mathrm{p}_{\mathrm{j}}^{+}=\mathrm{j} \text {. günde alınan protein miktarı hedefinden pozitif sapma } & \mathrm{j}=1,2, \ldots, 20 \\
\mathrm{t}_{\mathrm{j}}^{-}=\mathrm{j} \text {. günde alınan tia min miktarı hedefinden negatif sapma } & \mathrm{j}=1,2, \ldots ., 20 \\
\mathrm{t}_{\mathrm{j}}^{+}=\mathrm{j} \text {. günde alınan tia min miktarı hedefinden pozitif sapma } & \mathrm{j}=1,2, \ldots, 20 \\
\mathrm{cv}_{\mathrm{j}}^{-}=\mathrm{j} \text {. günde alınan C vita mini miktarı hedefinden negatif sapma } & \mathrm{j}=1,2, \ldots ., 20 \\
\mathrm{cv}_{\mathrm{j}}^{+}=\mathrm{j} \text {. günde alınan C vita mini miktarı hedefinden pozitif sapma }
\end{array}
$$

Amaç Fonksiyonu:

$$
\mathrm{Z}_{\min }=\mathrm{m}^{+}+\sum_{\mathrm{j}=1}^{20}\left(\mathrm{e}_{\mathrm{j}}^{+}+\mathrm{e}_{\mathrm{j}}^{-}+\mathrm{p}_{\mathrm{j}}^{+}+\mathrm{p}_{\mathrm{j}}^{-}+\mathrm{t}_{\mathrm{j}}^{+}+\mathrm{t}_{\mathrm{j}}^{-}+\mathrm{cv}_{\mathrm{j}}^{+}+\mathrm{cv}_{\mathrm{j}}^{-}\right)
$$

\section{Hedef Kisitlarl:}

$$
\begin{aligned}
& \sum_{\mathrm{j}=1}^{20} \sum_{\mathrm{i}=1}^{22} \tilde{\mathrm{C}}_{\mathrm{i}} * \mathrm{BG}_{\mathrm{ij}}+\sum_{\mathrm{j}=1}^{20} \sum_{\mathrm{i}=1}^{18} \tilde{\mathrm{C}}_{\mathrm{i}} * \mathrm{IG}_{\mathrm{ij}} \sum_{\mathrm{j}=1}^{20} \sum_{\mathrm{i}=1}^{24} \tilde{\mathrm{C}}_{\mathrm{i}} * \ddot{U}_{\mathrm{ij}}-\mathrm{m}_{\mathrm{j}}^{+}+\mathrm{m}_{\mathrm{j}}^{-}=27,34+5,04 \mu \\
& \sum_{\mathrm{i}=1}^{22} \tilde{\mathrm{E}}_{\mathrm{i}} * \mathrm{BG}_{\mathrm{ij}}+\sum_{\mathrm{i}=1}^{18} \tilde{\mathrm{E}}_{\mathrm{i}} * \dot{\mathrm{I}}_{\mathrm{ij}}+\sum_{\mathrm{i}=1}^{24} \tilde{\mathrm{E}}_{\mathrm{i}} * \ddot{\mathrm{U}} \mathrm{G}_{\mathrm{ij}}+\mathrm{e}_{\mathrm{i}}^{-}-\mathrm{e}_{\mathrm{i}}^{+}=712,5+75 \mu \quad \mathrm{j}=1,2, \ldots ., 20 \\
& \sum_{\mathrm{i}=1}^{22} \tilde{\mathrm{P}}_{\mathrm{i}} * \mathrm{BG}_{\mathrm{ij}}+\sum_{\mathrm{i}=1}^{18} \tilde{\mathrm{P}}_{\mathrm{i}} * \dot{\mathrm{IG}}_{\mathrm{ij}}+\sum_{\mathrm{i}=1}^{24} \tilde{\mathrm{P}}_{\mathrm{i}} * \ddot{\mathrm{U}} \mathrm{G}_{\mathrm{ij}}+\mathrm{p}_{\mathrm{i}}^{-}-\mathrm{p}_{\mathrm{i}}^{+}=21,57+2,27 \mu \quad \mathrm{j}=1,2, \ldots ., 20 \\
& \sum_{\mathrm{i}=1}^{22} \tilde{\mathrm{T}}_{\mathrm{i}} * \mathrm{BG}_{\mathrm{ij}}+\sum_{\mathrm{i}=1}^{18} \tilde{\mathrm{T}}_{\mathrm{i}} * \dot{\mathrm{I}}_{\mathrm{ij}}+\sum_{\mathrm{i}=1}^{24} \tilde{\mathrm{T}}_{\mathrm{i}} * \ddot{\mathrm{U}} \mathrm{G}_{\mathrm{ij}}+\mathrm{t}_{\mathrm{i}}^{-}-\mathrm{t}_{\mathrm{i}}^{+}=0,36+0,04 \mu \quad \mathrm{j}=1,2, \ldots ., 20 \\
& \sum_{\mathrm{i}=1}^{22} \tilde{\mathrm{C}} \mathrm{V}_{\mathrm{i}} * \mathrm{BG}_{\mathrm{ij}}+\sum_{\mathrm{i}=1}^{18} \tilde{\mathrm{C}} \mathrm{V}_{\mathrm{i}} * \dot{\mathrm{I}}_{\mathrm{ij}}+\sum_{\mathrm{i}=1}^{24} \tilde{\mathrm{C}} \mathrm{V}_{\mathrm{i}} * \ddot{\mathrm{U}} \mathrm{G}_{\mathrm{ij}}+\mathrm{cv}_{\mathrm{i}}^{-}-\mathrm{cv}_{\mathrm{i}}^{+}=32,3+3,4 \mu \quad \mathrm{j}=1,2, \ldots ., 20
\end{aligned}
$$

\section{Model Kisitlart:}

$$
\begin{array}{ll}
\sum_{\mathrm{i}=1}^{22} \mathrm{BG}_{\mathrm{ij}}=1 & \mathrm{j}=1,2, \ldots, 20 \\
1 \leq \sum_{\mathrm{i}=1}^{18} \dot{\mathrm{IG}}_{\mathrm{ij}} \leq 2 & \mathrm{j}=1,2, \ldots, 20 \\
\sum_{\mathrm{i}=1}^{24} \mathrm{U}_{\mathrm{ij}}=1 & \mathrm{j}=1,2, \ldots, 20
\end{array}
$$




$$
\begin{aligned}
& \sum_{\mathrm{j}=1}^{20} \mathrm{BG}_{\mathrm{ij}} \leq 1 \\
& \mathrm{i}=1,2, \ldots ., 22 \\
& 1 \leq \sum_{\mathrm{j}=1}^{20} \dot{\mathrm{IG}}_{\mathrm{ij}} \leq 3 \\
& \mathrm{i}=1,2, \ldots ., 18 \\
& \sum_{j=1}^{20} \ddot{U}_{i j} \leq 1 \\
& \mathrm{i}=1,2, \ldots ., 24 \\
& \sum_{j=n}^{n+3} B_{i j}=1 \\
& \mathrm{n}=1,2, \ldots ., 17 \\
& \mathrm{i}=1,2, \ldots ., 22 \\
& \sum_{j=n}^{n+3} \dot{I G}_{i j}=1 \\
& \mathrm{n}=1,2, \ldots ., 17 \\
& \mathrm{i}=1,2, \ldots ., 18 \\
& \sum_{j=n}^{n+3} \ddot{U} G_{i j}=1 \\
& \mathrm{n}=1,2, \ldots ., 17 \\
& \mathrm{i}=1,2, \ldots ., 24 \\
& \sum_{\mathrm{i}=13}^{22} \mathrm{BG}_{\mathrm{ij}}+\sum_{\mathrm{i}=1}^{6} \mathrm{I}_{\mathrm{ij}} \leq 1 \\
& \mathrm{j}=1,2, \ldots, 20 \\
& \sum_{\mathrm{i}=19}^{20} \mathrm{FG}_{\mathrm{ij}}+\sum_{\mathrm{i}=2}^{3} \mathrm{SG}_{\mathrm{ij}}+\sum_{\mathrm{i}=12}^{13} \mathrm{SG}_{\mathrm{ij}} \leq 1 \\
& \mathrm{j}=1,2, \ldots, 20 \\
& \sum_{\mathrm{i}=21}^{22} \mathrm{BG}_{\mathrm{ij}}+\sum_{\mathrm{i}=1}^{6} \dot{\mathrm{I}} \mathrm{G}_{\mathrm{ij}}+\sum_{\mathrm{i}=14}^{18} \dot{\mathrm{I}} \mathrm{G}_{\mathrm{ij}} \leq 1 \\
& \mathrm{j}=1,2, \ldots, 20 \\
& \sum_{\mathrm{i}=12}^{18} \dot{\mathrm{IG}}_{\mathrm{ij}}+\sum_{\mathrm{i}=1}^{4} \ddot{\mathrm{UG}}_{\mathrm{ij}} \leq 1 \\
& j=1,2, \ldots ., 20 \\
& \sum_{\mathrm{i}=1}^{6} \dot{\mathrm{I}}_{\mathrm{ij}}+\sum_{\mathrm{i}=5}^{8} \ddot{\mathrm{UG}}_{\mathrm{ij}} \leq 1 \\
& j=1,2, \ldots ., 20 \\
& \sum_{\mathrm{i}=13}^{22} \mathrm{BG}_{\mathrm{ij}}+\sum_{\mathrm{i}=5}^{8} \ddot{\mathrm{UG}}_{\mathrm{ij}} \leq 1 \\
& \mathrm{j}=1,2, \ldots ., 20 \\
& \sum_{\mathrm{i}=7}^{11} \dot{\mathrm{IG}}_{\mathrm{ij}}+\ddot{\mathrm{U}}_{22 \mathrm{j}} \leq 1 \\
& \mathrm{j}=1,2, \ldots ., 20 \\
& \sum_{\mathrm{i}=1}^{6} \mathrm{BG}_{\mathrm{ij}}+\mathrm{BG}_{10 \mathrm{j}}+\mathrm{BG}_{12 \mathrm{j}}+\mathrm{BG}_{16 \mathrm{j}}+\dot{\mathrm{I}}_{6 \mathrm{j}}+\ddot{\mathrm{UG}}_{8 \mathrm{j}} \leq 1 \\
& \mathrm{j}=1,2, \ldots ., 20 \\
& \mathrm{BG}_{15 \mathrm{j}}+\mathrm{BG}_{20 \mathrm{j}}+\dot{\mathrm{IG}}_{5 \mathrm{j}}+\dot{\mathrm{IG}}_{8 \mathrm{j}}+\ddot{\mathrm{UG}}_{22 \mathrm{j}}+\ddot{\mathrm{UG}}_{23 \mathrm{j}} \leq 1 \quad \mathrm{j}=1,2, \ldots ., 20 \\
& \mathrm{BG}_{4 \mathrm{j}}+\mathrm{BG}_{7 \mathrm{j}}+\mathrm{BG}_{11 \mathrm{j}}+\sum_{\mathrm{i}=19}^{20} \mathrm{BG}_{\mathrm{ij}}+\sum_{\mathrm{i}=2}^{3} \dot{\mathrm{I}}_{\mathrm{ij}}+\dot{\mathrm{I}}_{8 \mathrm{j}}+\dot{\mathrm{I}}_{12 \mathrm{j}}+\ddot{\mathrm{U}}_{1 \mathrm{j}} \leq 1 \quad \mathrm{j}=1,2, \ldots ., 20 \\
& \mathrm{BG}_{3 \mathrm{j}}+\sum_{\mathrm{i}=7}^{9} \mathrm{BG}_{\mathrm{ij}}+\dot{\mathrm{I}}_{6 \mathrm{j}} \leq 1 \\
& \mathrm{j}=1,2, . ., 20 \\
& \sum_{\mathrm{i}=8}^{9} \mathrm{BG}_{\mathrm{ij}}+\sum_{\mathrm{i}=16}^{17} \mathrm{BG}_{\mathrm{ij}}+\sum_{\mathrm{i}=20}^{21} \mathrm{BG}_{\mathrm{ij}}+\dot{\mathrm{IG}}_{4 \mathrm{j}} \leq 1 \\
& \mathrm{j}=1,2, . ., 20
\end{aligned}
$$




\section{SONUÇLAR}

Modelin 3 farklı üyelik derecesi $(0,0,5$ ve 1$)$ için çözülmesi sonucu elde edilen menüler ve sapma değişkenlerinin değerleri tablo 4'te verilmiştir. Tablo 4'te; $\mu=0$ sütunundaki menüleruygulanması neredeyse olanaksız (maliyetlerinen az, bu maliyetlerle yapılan yemeklerin enerji ve besin ögesi değerlerinin en fazla olması durumu olduğu için), $\mu=1$ sütunundaki menüler ise uygulanabilirliği en kolay olan menüleri ifade etmektedir.

Bu üyelik dereceleri için elde edilen 20 günlük kişi başı maliyetler ise sırasıyla, 26,84 TL (m $=0,5), 29,01 \mathrm{TL}\left(\mathrm{m}^{-}=0,85\right)$, ve 31,27 $\mathrm{TL}\left(\mathrm{m}^{-}=1,11\right)$ olarak bulunmuştur. Yani menü planlama koşullarına uymak kaydıyla; işçilik, ekmek, sabit giderler vb. hariç 1 kişi için 20 günlük menü maliyetinin 26,84 TL'nin altına inmeyeceği, 31,27 TL'nin üzerine de çıkmayacağı söylenebilir. Kurulan modeldeki maliyet değerlerinin Oruç vd.’nin (2012) çalışmasında elde edilen maliyet değerlerinden daha az olduğu görülmektedir. Bunun ana sebebinin modelin kurulumunda, bulanık doğrusal programlama yerine hedef programlamanın kullanılmasının olduğu söylenebilir. Çünkü model bulanık doğrusal programlama ile kurulduğu zaman, bu çalışmada hedef olarak alınan enerji ve besin ögesi değerleri kısıt olarak alınmaktadır.Bu da hedeflerden negatif sapmaya hiç izin verilmemesi sonucunu doğurmaktadır.

Tablo 4'te görüldügü gibi, bazı enerji ve besin ögesi değerlerinden pozitif sapmalar fazladır. Bu durum, modele alınması gereken enerji ve besin ögesi değerlerinin belirli bir oranından daha fazla pozitif veya negatif sapmaya izin verilmemesi kısıtları eklenerek engellenebilir. Bu çalışmanın hazırlanması sürecinde de bu yönde kısıtlar eklenmiş fakat model çözümsüz çıkmıştır. Bunun ana sebebi çalışmada kullanılan yemek çeşidi sayısının az olmasıdır.

Bilindiği gibi günümüzde hâlâ yeterli ve sağlıklı verilere ulaşmak mümkün olamamaktadır. Ancak, bilişim teknolojilerinin gelişmesiyle birliktedoğru veri toplama ve arşivlemenin öneminin anlaşıldığı da bir gerçektir.Bu anlamda gelecekte daha fazla yemek çeşidi ve sağlıklı veriler ile model daha etkin hale getirilebilir.

$\mathrm{Bu}$ çalışmada da görüldüğü gibi,menü planlama karmaşı bir süreçten oluşmaktadır.Planlamanın hedef programlama ile yapılmasının,el ile yapılan bir planlamanın sebep olabileceği olası hataları ortadan kaldıracağı açıktır. Ayrıca, matematiksel modelleme ciddi bir zaman tasarrufu da sağlamaktadır.Bunların dışında, verilerdeki bulanıklıkların dikkate alınmasının modellere esneklik kazandırdığg görülmektedir. 
Tablo 2.Yemek Bilgileri

\begin{tabular}{|c|c|c|c|c|c|c|c|c|}
\hline & \multirow{3}{*}{$\begin{array}{c}\text { Yemek } \\
\text { Kodları }\end{array}$} & \multirow{3}{*}{ Yemek Adları } & \multicolumn{4}{|c|}{$\begin{array}{l}\text { BİR PORSIYYON YEMEĞİN TOPLAM } \\
\text { ENERJİ VE BESİN DEĞERLERİ }\end{array}$} & \multirow{3}{*}{$\begin{array}{l}\text { YEMEK } \\
\text { MALIYETI } \\
\text { (TL) }\end{array}$} \\
\hline & & & & $\begin{array}{l}\text { Enerji } \\
\text { (kkal) }\end{array}$ & $\begin{array}{l}\text { Protein } \\
\text { (gr) }\end{array}$ & $\begin{array}{c}\text { Tiamin } \\
(\mathrm{mg})\end{array}$ & $\underset{(\mathrm{mg})}{\text { C Vitamini }}$ & \\
\hline & & & & $\mathbf{E}_{\mathrm{i}}$ & $\mathbf{P}_{i}$ & $\mathbf{T}_{\mathbf{i}}$ & $\mathbf{N}_{\mathrm{i}}$ & \\
\hline \multirow{22}{*}{ 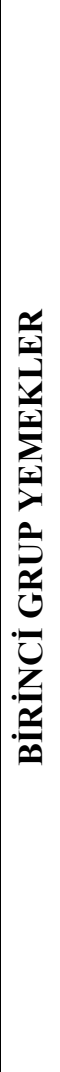 } & \multirow{12}{*}{ 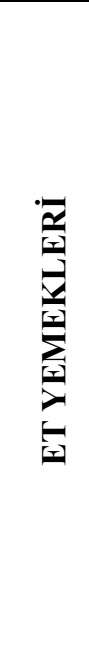 } & $\mathbf{B G}_{1}$ & Söğüş Et (P.. Püre G.) & 339 & 19,6 & 0,1 & 12,4 & 1,227 \\
\hline & & $\mathbf{B G}_{2}$ & Rosto Et (Patates G.) & 348 & 18,4 & 0,1 & 12,3 & 1,191 \\
\hline & & $\mathbf{B G}_{3}$ & Dana Haşlama & 369,4 & 36,6 & 0,1 & 8,8 & 1,209 \\
\hline & & $\mathbf{B G}_{4}$ & $\begin{array}{l}\text { Kadınbudu Köfte } \\
\text { (Patates Püre G.) }\end{array}$ & 417 & 16,2 & 0,2 & 15,2 & 0,985 \\
\hline & & $\mathbf{B G}_{5}$ & F. Köfte (P. Püre G.) & 309 & 15,4 & 0,2 & 15,2 & 0,905 \\
\hline & & $\mathbf{B G}_{6}$ & İzmir Köfte & 343 & 14,6 & 0,2 & 14,1 & 0,877 \\
\hline & & $\mathbf{B G}_{7}$ & \begin{tabular}{|c|}
$\begin{array}{c}\text { Kuzu Firın (P. Pilavı } \\
\text { G.) }\end{array}$ \\
\end{tabular} & 416,6 & 43 & 0,2 & 0,3 & 1,708 \\
\hline & & $\mathbf{B G}_{8}$ & Piliç Şnitzel (Sebze G.) & 534,2 & 54,7 & 0,3 & 18,1 & 1,047 \\
\hline & & BG $_{9}$ & Piliç Izgara (Sebze G.) & 337,6 & 47,8 & 0,2 & 18,4 & 0,978 \\
\hline & & $\mathbf{B G}_{10}$ & Haşlama Tavuk & 259 & 26,2 & 0,2 & 14,6 & 0,646 \\
\hline & & $\mathbf{B G}_{\mathbf{1 1}}$ & $\begin{array}{l}\begin{array}{l}\text { Soya Soslu Tavuk } \\
\text { (Pirinç Pilavı G.) }\end{array} \\
\end{array}$ & 315,1 & 39,9 & 0,1 & 0,1 & 0,795 \\
\hline & & $\mathbf{B G}_{12}$ & $\begin{array}{c}\text { Alabalık Tava (Sebze } \\
\text { G.) }\end{array}$ & 489,6 & 52,3 & 0,3 & 33 & 0,916 \\
\hline & \multirow{10}{*}{. } & $\mathbf{B G}_{13}$ & Kıymalı Kapuska & 190 & 10,3 & 0,1 & 65,8 & 0,662 \\
\hline & & $\mathbf{B G}_{14}$ & Kıymalı Karnabahar & 187 & 11,3 & 0,2 & 121,3 & 0,799 \\
\hline & & $\mathbf{B G}_{15}$ & Kıymalı Ispanak & 276 & 15,6 & 0,2 & 77,8 & 0,853 \\
\hline & & $\mathbf{B G}_{\mathbf{1 6}}$ & Etli Türlü & 221 & 10,1 & 0,1 & 31,7 & 0,700 \\
\hline & & $\mathbf{B G}_{17}$ & Kıymalı Taze Fasulye & 222 & 11,1 & 0,2 & 41,3 & 0,774 \\
\hline & & $\mathbf{B G}_{18}$ & Karnıyarık & 270 & 9,6 & 0,1 & 22,8 & 0,845 \\
\hline & & $\mathbf{B G}_{19}$ & Etli Biber Dolması & 226 & 11,2 & 0,1 & 84,2 & 0,908 \\
\hline & & $\mathbf{B G}_{20}$ & Etli Kabak Dolması & 247 & 11,1 & 0,1 & 21,7 & 0,862 \\
\hline & & $\mathbf{B G}_{21}$ & Etli Kuru Fasulye & 336 & 19,1 & 0,3 & 3,3 & 0,518 \\
\hline & & $\mathbf{B G}_{22}$ & Etli Nohut & 350 & 17,4 & 0,3 & 2,3 & 0,516 \\
\hline \multirow{18}{*}{ 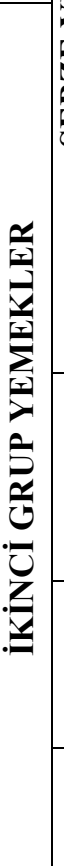 } & \multirow{6}{*}{ : } & $\dot{\mathbf{I}} \mathbf{G}_{1}$ & İmambayıldı & 194 & 2,1 & 0,1 & 18,3 & 0,293 \\
\hline & & $\mathbf{I} \mathbf{G}_{2}$ & $\begin{array}{c}\text { Zeytinyağlı Biber } \\
\text { Dolması }\end{array}$ & 265 & 4,6 & 0,1 & 88,8 & 0,444 \\
\hline & & $\mathbf{I}_{\mathbf{3}}$ & $\begin{array}{c}\text { Zeytinyağlı Yaprak } \\
\text { Dolması }\end{array}$ & 268 & 4,7 & 0,1 & 42,1 & 0,327 \\
\hline & & $\mathbf{I}_{4}$ & $\begin{array}{l}\text { Zeytinyağll Taze } \\
\text { Fasulye }\end{array}$ & 177 & 3,5 & 0,1 & 38 & 0,267 \\
\hline & & İG & Zeytinyağlı Bakla & 266 & 11,3 & 0,5 & 46,5 & 0,362 \\
\hline & & $\dot{\mathbf{I}} \mathbf{G}_{6}$ & Zeytinyağlı Barbunya & 328 & 13,3 & 0,2 & 10 & 0,274 \\
\hline & \multirow{5}{*}{ 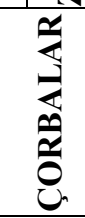 } & $\dot{\mathbf{I}} \mathbf{G}_{7}$ & Domates Çorbası & 161 & 3,4 & 0,1 & 1,3 & 0,094 \\
\hline & & İG 8 & Yayla Çorbası & 115 & 3,3 & 0,1 & 0,3 & 0,092 \\
\hline & & $\dot{\mathbf{I}} \mathbf{G}_{9}$ & K. Mercimek Çorbası & 183 & 7,9 & 0,2 & 2,2 & 0,063 \\
\hline & & $\dot{\mathbf{I}} \mathbf{G}_{\mathbf{1 0}}$ & Şehriye Çorbası & 115 & 1,8 & 0 & 0,3 & 0,066 \\
\hline & & $\dot{\mathbf{I}} \mathbf{G}_{11}$ & Un Çorbası & 184 & 2,8 & 0,1 & 0 & 0,043 \\
\hline & \multirow{4}{*}{ 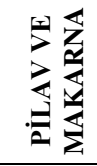 } & $\dot{\mathbf{I}} \mathbf{G}_{12}$ & Pirinç Pilavı & 336 & 4,7 & 0,1 & 0 & 0,129 \\
\hline & & $\dot{\mathbf{I}} \mathbf{G}_{13}$ & Bulgur Pilavi & 291 & 6,5 & 0,2 & 10,5 & 0,068 \\
\hline & & $\dot{\mathbf{I}} \mathbf{G}_{14}$ & Firında Makarna & 505 & 19,4 & 0,2 & 0,4 & 0,433 \\
\hline & & $\dot{\mathbf{I}} \mathbf{G}_{15}$ & Peynirli Makarna & 354 & 10,7 & 0,1 & 0 & 0,208 \\
\hline & \multirow{3}{*}{ 举 } & $\dot{\mathbf{I}} \mathbf{G}_{16}$ & Tepsi Böreği & 421 & 15 & 0,3 & 3,3 & 0,610 \\
\hline & & $\dot{\mathbf{I}} \mathbf{G}_{17}$ & Su Böreği & 293,1 & 9,4 & 0,1 & 6,7 & 0,237 \\
\hline & & $\mathbf{I}_{\mathbf{1 8}}$ & Ispanaklı Börek & 368,5 & 11,1 & 0,1 & 22,4 & 0,326 \\
\hline
\end{tabular}




\begin{tabular}{|c|c|c|c|c|c|c|c|c|}
\hline & & \multirow{3}{*}{$\begin{array}{l}\text { Yemek } \\
\text { Kodları }\end{array}$} & \multirow{3}{*}{ Yemek Adları } & \multicolumn{4}{|c|}{$\begin{array}{l}\text { BİR PORSIYYON YEMEĞİN TOPLAM } \\
\text { ENERJİ VE BESINN DEĞERLERİ }\end{array}$} & \multirow{3}{*}{$\begin{array}{c}\text { YEMEK } \\
\text { MALIYETI } \\
\text { (TL) }\end{array}$} \\
\hline & & & & $\begin{array}{c}\text { Enerji } \\
\text { (kkal) }\end{array}$ & $\begin{array}{l}\text { Protein } \\
\text { (gr) }\end{array}$ & $\begin{array}{c}\text { Tiamin } \\
\text { (mg) }\end{array}$ & \begin{tabular}{|c|} 
C Vitamini \\
$(\mathrm{mg})$
\end{tabular} & \\
\hline & & & & $\mathbf{E}_{\mathbf{i}}$ & $\mathbf{P}_{\mathbf{i}}$ & $\mathbf{T}_{\mathbf{i}}$ & $\mathbf{N}_{\mathbf{i}}$ & \\
\hline \multirow{24}{*}{ هـ } & \multirow{4}{*}{ 量 } & $\ddot{\mathbf{U}} \mathbf{G}_{1}$ & Sütlaç & 347 & 8,4 & 0,1 & 2,2 & 0,372 \\
\hline & & $\ddot{\mathbf{U}} \mathbf{G}_{2}$ & Tulumba & 512,3 & 4,3 & 0 & 0,2 & 0,218 \\
\hline & & $\ddot{\mathbf{U}} \mathbf{G}_{\mathbf{3}}$ & Şekerpare & 482,6 & 5 & 0 & 0,2 & 0,215 \\
\hline & & $\ddot{\mathbf{U}} \mathbf{G}_{4}$ & Revani & 367,6 & 4,8 & 0 & 0,2 & 0,208 \\
\hline & \multirow{4}{*}{ 造 } & $\ddot{\mathbf{U}} \mathbf{G}_{5}$ & Karışık Salata & 123 & 1,3 & 0,1 & 28,8 & 0,278 \\
\hline & & $\ddot{\mathbf{U}} \mathbf{G}_{6}$ & Kıvırcık Salata & 84 & 0,9 & 0,1 & 10,6 & 0,241 \\
\hline & & $\ddot{\mathbf{U}} \mathbf{G}_{7}$ & Çoban Salata & 113 & 1,8 & 0,1 & 52,2 & 0,301 \\
\hline & & $\ddot{\mathbf{U}} \mathbf{G}_{8}$ & Patates Salatası & 184,9 & 3,8 & 0,2 & 63,5 & 0,261 \\
\hline & \multirow{13}{*}{ 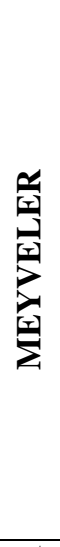 } & $\ddot{\mathbf{U}} \mathbf{G}_{9}$ & Elma & 101 & 0,5 & 0 & 10 & 0,281 \\
\hline & & $\ddot{\mathbf{U}} \mathbf{G}_{10}$ & Kayısı & 72 & 0,9 & 0 & 11 & 0,270 \\
\hline & & $\ddot{\mathbf{U}} \mathbf{G}_{11}$ & Muz & 153,3 & 1,8 & 0 & 13,8 & 0,529 \\
\hline & & $\ddot{\mathbf{U}} \mathbf{G}_{12}$ & Kiraz & 63 & 1,6 & 0 & 14 & 0,413 \\
\hline & & $\ddot{\mathbf{U}} \mathbf{G}_{13}$ & Üzüm & 108 & 0,9 & 0,1 & 4 & 0,300 \\
\hline & & $\ddot{\mathbf{U}} \mathbf{G}_{14}$ & Kavun & 77 & 1,4 & 0,1 & 80 & 0,233 \\
\hline & & $\ddot{\mathbf{U}} \mathbf{G}_{15}$ & Karpuz & 73 & 1,3 & 0,1 & 15 & 0,175 \\
\hline & & $\ddot{\mathbf{U}} \mathbf{G}_{16}$ & Portakal & 69 & 1,1 & 0,1 & 83 & 0,186 \\
\hline & & $\ddot{\mathbf{U}} \mathbf{G}_{17}$ & Mandalina & 70 & 1 & 0,1 & 46 & 0,238 \\
\hline & & $\ddot{\mathbf{U}} \mathbf{G}_{18}$ & Şeftali & 83 & 1,1 & 0 & 39 & 0,247 \\
\hline & & $\ddot{\mathbf{U}} \mathbf{G}_{19}$ & Armut & 113 & 0,5 & 0 & 10 & 0,248 \\
\hline & & $\ddot{\mathbf{U}} \mathbf{G}_{20}$ & Çilek & 57 & 1,1 & 0 & 100 & 0,180 \\
\hline & & $\ddot{\mathbf{U}} \mathbf{G}_{21}$ & Erik & 59 & 0,7 & 0 & 9 & 0,188 \\
\hline & \multirow{3}{*}{ טִ } & $\ddot{\mathbf{U}} \mathbf{G}_{22}$ & Ayran & 45 & 2,6 & 0 & 0 & 0,250 \\
\hline & & $\ddot{\mathbf{U}} \mathbf{G}_{23}$ & Yoğurt & 194 & 10,56 & 0,2 & 3 & 0,330 \\
\hline & & Ü $\mathbf{G}_{24}$ & Turşu & 10 & 0,6 & 0 & 0,7 & 0,480 \\
\hline
\end{tabular}

Kaynak: Oruç vd., 2012: 17-19, Şenol 2011, 74-125. 
Tablo 3. Bulanık Veriler ve Üyelik Fonksiyonları

\begin{tabular}{|c|c|c|c|c|c|c|c|c|c|c|c|c|c|c|c|c|c|c|c|c|}
\hline \multirow{2}{*}{$\begin{array}{l}\text { Yemek } \\
\text { Kodları }\end{array}$} & \multicolumn{4}{|c|}{ Enerji (kkal) } & \multicolumn{4}{|c|}{ Protein (gr) } & \multicolumn{4}{|c|}{ Tiamin $(\mathbf{m g})$} & \multicolumn{4}{|c|}{ C Vitamini (mg) } & \multicolumn{4}{|c|}{ YEMEK MALIYETI (TL) } \\
\hline & $\mathbf{E}^{\mathrm{L}}$ & $\mathbf{E}^{\mathrm{U}}$ & & \begin{tabular}{|l|l|} 
Üyelik Fonk. \\
\end{tabular} & $\mathbf{P}^{\mathrm{L}}$ & $\mathbf{P}^{\mathbf{U}}$ & & Üyelik Fonk. & $T^{L}$ & $\mathbf{T}^{\mathbf{U}}$ & & Üyelik Fonk. & $\mathrm{CV}^{\mathrm{L}}$ & $\mathbf{C V}^{\mathbf{U}}$ & & Üyelik Fonk. & $\mathbf{C}^{\mathbf{L}}$ & & & Üyelik Fonk. \\
\hline $\mathbf{B G}_{1}$ & 322,05 & 355,95 & 33,90 & $355,95-33,9 \mu$ & 18,62 & 20,58 & 1,96 & $20,58-1,96 \mu$ & 0,10 & 0,11 & 0,01 & $0,11-0,01 \mu$ & 11,78 & 13,02 & 1,24 & $13,02-1,24 \mu$ & 1,17 & 1,29 & 0,12 & $1,17+0,12 \mu$ \\
\hline $\mathbf{B G}_{\mathbf{2}}$ & 30,60 & 65,40 & 34,80 & $65,4-34,8 \mu$ & 17,48 & 19,32 & 1,84 & $32-1,84 \mu$ & 0,10 & 0,11 & 0,01 & $11-0,01 \mu$ & 11,69 & 12,92 & 1,23 & $2,915-1,23 \mu$ & 1,13 & 1,25 & 0,12 & $13+0,12 \mu$ \\
\hline $\mathbf{B G}_{3}$ & 0,93 & 387,87 & 36,94 & $387,87-36,94 \mu$ & 34,77 & 38,43 & 3,66 & $, 43-3,66 \mu$ & 0,10 & 0,11 & 0,01 & $-0,01 \mu$ & 8,36 & 9,24 & 0,88 & $9,24-0,88 \mu$ & 1,15 & 1,27 & 0,12 &, $12 \mu$ \\
\hline $\mathbf{B G}_{\mathbf{4}}$ & 6,15 & 437,85 & 41,70 & $437,85-41,7 \mu$ & 15,39 & 17,01 & 1,62 & $1-1,62 \mu$ & 0,19 & 0,21 & ( &, $02 \mu$ & 14,44 & 15,96 & 1,52 & $15,96-1,52 \mu$ & 0,94 & 1,03 & 0,1 & $0,1 \mu$ \\
\hline $\mathbf{B G}_{5}$ & 93,55 & 324,45 & 30,90 & $324,45-30,9 \mu$ & 14,63 & 16,17 & 1,54 & $16,17-1,54 \mu$ & 0,19 & 0,21 & 0,02 & $0,21-0,02 \mu$ & 14,44 & 15,96 & 1,52 & $15,96-1,52 \mu$ & 0,86 & 0,95 & 0,09 & $86+0,09 \mu$ \\
\hline $\mathbf{B G}_{6}$ & 25,85 & \begin{tabular}{|l|}
360,15 \\
\end{tabular} & 34,30 & $360,15-34,3 \mu$ & 13,87 & 15,33 & 1,46 & $15,33-1,46 \mu$ & 0,19 & 0,21 & 0,02 & $0,21-0,02 \mu$ & 13,40 & 14,81 & 1,41 & $14,81-1,41 \mu$ & 0,83 & 0,92 & 0,09 & $83+0,09 \mu$ \\
\hline $\mathbf{B G}_{7}$ & 95,77 & \begin{tabular}{|l|}
437,43 \\
\end{tabular} & 41,66 & $437,43-41,66 \mu$ & 40,85 & 45,15 & 4,30 & $45,15-4,3 \mu$ & 0,19 & 0,21 & 0,02 & $-0,02 \mu$ & 0,29 & 0,32 & 0,03 & $0,312-0,03 \mu$ & 1,62 & 1,79 & 0,17 & $-0,17 \mu$ \\
\hline $\mathbf{B G}_{8}$ & 07,49 & 560,91 & 53,42 & $560,91-53,42 \mu$ & 51,97 & 57,44 & 5,47 & $57,44-5,47 \mu$ & 0,29 & 0,32 & & & 17,20 & 19,01 & 1,81 & & 0,99 & 1,1 & 0,1 & $+0,1 \mu$ \\
\hline & 20,72 & 354,48 & 33,76 & 354, & 45,41 & 50,19 & 4,78 & & 0,19 & 0,21 & & & 17,48 & 19,32 & & & 0,93 & 03 & 0,1 & $0,1 \mu$ \\
\hline BC & 46,05 & \begin{tabular}{|l|}
271,95 \\
\end{tabular} & 25,90 & 271 & 24,89 & 27,51 & 2,6 & $2 \mu$ & 0,19 & 0,2 & & & 13,87 & 15,33 & & $6 \mu$ & 0,61 & 0,68 & 06 & $06 \mu$ \\
\hline $\mathbf{B C}$ & 9,35 & 330,86 & 31,51 & 330,8 & 37,91 & 41,90 & 3,99 & $9 \mu$ &, 10 & 0 & & & 0,10 & 0,11 & 0 & & 0,76 &, 83 & 08 & \\
\hline $\mathbf{B G}_{12}$ & 65,12 & 514,08 & 48,96 & 514, & 49,69 & 54,92 & 5,23 & $23 \mu$ & 0,29 & 0 & & & 1,35 & 34,65 & & $34,65-3,3 \mu$ & 0,87 & 0,96 &, 09 & $09 \mu$ \\
\hline $\mathbf{B G}_{13}$ & 0,50 & \begin{tabular}{|l|}
199,50 \\
\end{tabular} & 19,00 & $199,5-19 \mu$ & 9,79 & 10,82 & 1,03 & & 0,10 & 0 & & & 62,51 & 69,09 & 6,58 & & 0,63 & 0,7 & 07 & \\
\hline $\mathbf{B G}_{14}$ & 77,65 & \begin{tabular}{|l|}
196,35 \\
\end{tabular} & 18,70 & $196,35-18,7 \mu$ & 10,74 & 11,87 & 1,13 & $-1,13 \mu$ & 0,19 & 0,21 & 0 &, $02 \mu$ & 115,24 & 127,37 & 12,13 & $127,37-12,13 \mu$ & 0,76 & 0,84 & 0,08 &, $08 \mu$ \\
\hline $\mathbf{B G}_{15}$ & 52,20 & 289,80 & 27,60 & 289 , & 14,82 & 16,38 & 1,56 & & 0,19 & 0,21 & & & 73,91 & 81,69 & 7,78 &, $78 \mu$ & 0,81 & 0,9 &, 09 &, $09 \mu$ \\
\hline $\mathbf{B G}_{16}$ & & & 22,10 & & 9,60 & 10,61 & 1,01 & & & 0,11 & & & & 33,29 & & & 0,67 & 0,74 & 07 & \\
\hline BC & 0,90 & \begin{tabular}{|l|}
233,10 \\
\end{tabular} & 22,20 & & 10,55 & 11,66 & 1,11 & & 0,19 & 0,21 & & & 39,24 & 43,37 & & & 0,74 & 81 & 08 & \\
\hline BG & 6,50 & \begin{tabular}{|l|}
283,50 \\
\end{tabular} & 27,00 & & 9,12 & 10,08 & 0,96 & & 0,10 & 0 , & & & 21,66 & 23,94 & & & 0,8 & 0,89 & 8 & \\
\hline $\mathbf{B G}_{1}$ & 4,70 & 237,30 & 22,60 & $6 \mu$ & 10,64 & 11,76 & 1,12 & $12 \mu$ & 0,10 & 0, & & $1 \mu$ & 79,99 & 88,41 & & $2 \mu$ & 0,86 & 0,95 &, 09 & $09 \mu$ \\
\hline $\mathbf{B G}_{20}$ & 4,65 & 259,35 & 24,70 &, $7 \mu$ & 10,55 & 11,66 & 1,11 & $11 \mu$ & 0,10 & & & & 20,62 & 22,79 & & $17 \mu$ & 0,82 & 0,91 & 0,09 & $09 \mu$ \\
\hline $\mathbf{B G}_{21}$ & 19,20 & 352,80 & 33,60 & $352,8-33,6 \mu$ & 18,15 & 20,06 & 1,91 & $-1,91 \mu$ & 0,29 & 0,32 & & $03 \mu$ & 3,14 & 3,47 & 1 & $33 \mu$ & 0,49 & 0,54 & 0,05 &, $05 \mu$ \\
\hline $\mathbf{B G}_{22}$ & 332,50 & 367,50 & 35,00 & $367,5-35 \mu$ & 16,53 & 18,27 & 1,74 & $27-1,74 \mu$ & 0,29 & 0,32 & 0,03 & $0,03 \mu$ & 2,19 & 2,42 & 0,23 & $2,42-0,23 \mu$ & 0,49 & 0,54 & 0,05 & $49+0,05 \mu$ \\
\hline $\mathbf{I} \mathbf{G}_{1}$ & 84,30 & 203,70 & 19,40 & $203,7-19,4 \mu$ & 2,00 & 2,21 & 0,21 & $-0,21 \mu$ & 0,10 & 0,11 & 0,01 & $0,01 \mu$ & 17,39 & 19,22 & 1,83 & $, 22-1,83 \mu$ & 0,28 & 0,31 & 0,03 & $28+0,03 \mu$ \\
\hline$\dot{\mathbf{I}} \mathbf{G}_{2}$ & 51,75 & 278,25 & 26,50 & & 4,37 & 4,83 & 0,46 & & 0,10 & 0,11 & & & 84,36 & 93,24 & . & & 0,42 & 0,47 & 04 & $42+0,04 \mu$ \\
\hline $\mathrm{I}_{3}$ & 4,60 & 281,40 & 26,80 & & 4,47 & 4,94 & 0,47 & & 0,10 & 0 , & & & 40,00 & 44,21 & 4, & & 0,31 & 0,34 & & \\
\hline & 8,15 & \begin{tabular}{|l|}
185,85 \\
\end{tabular} & 17,70 & $7,7 \mu$ & 3,33 & 3,68 & 0,3 & & 0,10 & & & & 6,10 & 9,90 & & & 0,25 & 0,28 & 3 & \\
\hline İG & 52,70 & 279,30 & 26,60 & $, 3-26,6 \mu$ & 10,74 & 11,87 & 1,1 & $87-1,13 \mu$ & 0,48 & 0 , & & $05 \mu$ & 44,18 & 48,83 & 4,65 & $8,83-4,65 \mu$ & 0,34 & 0,38 & 0,04 & \\
\hline$I_{\mathbf{I}} \mathbf{G}_{6}$ & 1,60 & 344,40 & 32,80 & $, 4-32,8 \mu$ & 12,64 & 13,97 & 1,33 & $7-1,33 \mu$ & 0,19 & 0,21 & & $0,02 \mu$ & 9,50 & 10,50 & & $10,5-1 \mu$ & 0,26 & 0,29 & 0,03 &, $03 \mu$ \\
\hline$\dot{\mathbf{I}} \mathbf{G}_{7}$ & 52,95 & \begin{tabular}{|l|}
169,05 \\
\end{tabular} & 16,10 & $69,05-16,1 \mu$ & 3,23 & 3,57 & 0,34 & $7-0,34 \mu$ & 0,10 & 0,11 & 0 , & $0,01 \mu$ & 1,24 & 1,37 & 0,13 & $37-0,13 \mu$ & 0,09 & 0,1 & 0,01 & $9+0,01 \mu$ \\
\hline İG 8 & 09,25 & 120,75 & 11,50 & $120,75-11,5 \mu$ & 3,14 & 3,47 & 0,33 & $3,47-0,33 \mu$ & 0,10 & 0,11 & 0,01 & $0,11-0,01 \mu$ & 0,29 & 0,32 & 0,03 & $0,32-0,03 \mu$ & 0,09 & 0,1 & 0,01 & $09+0,01 \mu$ \\
\hline İG9 & 173,85 & 192,15 & 18,30 & $192,15-18,3 \mu$ & 7,51 & 8,30 & 0,79 & $8,3-0,79 \mu$ & 0,19 & 0,21 & 0,02 & $21-0,02 \mu$ & 2,09 & 2,31 & 0,22 & $2,31-0,22 \mu$ & 0,06 & 0,07 & 0,01 & $, 06+0,01 \mu$ \\
\hline İG10 & 109,25 & 120,75 & 11,50 & 120 , & 1,71 & 1,89 & 0,18 & $0,18 \mu$ & 0 & 0 & 0 & 0 & 0,29 & 0,32 & 0,03 & $0,32-0,03 \mu$ & 0,06 & 0,07 & 0,01 & $06+0,01 \mu$ \\
\hline İG11 & 174,80 & 193,20 & 18,40 & $193,2-18,4 \mu$ & 2,66 & 2,94 & $\begin{array}{l}4 \quad 0,28 \\
\end{array}$ & $2,94-0,28 \mu$ & 0,10 & 0,11 & 0,01 & $0,11-0,01 \mu$ & 1 & 0 & 0 & & 0,04 & 0,05 & 0 & $0,04+0 \mu$ \\
\hline
\end{tabular}




\begin{tabular}{|c|c|c|c|c|c|c|c|c|c|c|c|c|c|c|c|c|c|c|c|c|}
\hline \multirow{3}{*}{$\begin{array}{c}\text { Yemek } \\
\text { Kodları } \\
\text { IG }_{12} \\
\end{array}$} & \multicolumn{4}{|c|}{ Enerji (kkal) } & \multicolumn{4}{|c|}{ Protein (gr) } & \multicolumn{4}{|c|}{ Tiamin $(\mathbf{m g})$} & \multicolumn{4}{|c|}{ C Vitamini (mg) } & \multicolumn{4}{|c|}{ YEMEK MALIYETİ (TL) } \\
\hline & $\mathbf{E}^{\mathrm{L}}$ & $\mathbf{E}^{\mathbf{U}}$ & $\mathbf{E}^{\mathbf{U}}-\mathbf{E}^{\mathbf{L}}$ & Üyelik Fonk. & $\mathbf{P}^{\mathbf{L}}$ & $\mathbf{P}^{\mathbf{U}}$ & & Üyelik Fonk. & $T^{\mathbf{L}}$ & $\mathbf{T}^{\mathbf{U}}$ & $\mathbf{T}^{\mathrm{U}}-\mathbf{T}^{\mathbf{L}}$ & Üyelik Fonk. & $\mathbf{C V}^{\mathbf{L}}$ & $\mathbf{C V}^{\mathrm{U}}$ & $\mathrm{CV}^{\mathrm{U}}-\mathrm{CV}^{\mathrm{L}}$ & Üyelik Fonk. & $\mathbf{C}^{\mathrm{L}}$ & & & Üyelik Fonk. \\
\hline & 319,20 & 352,80 & 33,60 & $352,8-33,6 \mu$ & 4,47 & 4,94 & 0,47 & $4,94-0,47 \mu$ & 0,10 & 0,11 & 0,01 & $0,11-0,01 \mu$ & 0 & 0 & 0 & 0 & 0,12 & 0,14 & 0,01 & $0,12+0,01 \mu$ \\
\hline$\dot{\mathbf{I}} \mathbf{G}_{13}$ & 276,45 & 305,55 & 29,10 & $305,55-29,1 \mu$ & 6,18 & 6,83 & 0,65 & $6,83-0,65 \mu$ & 0,19 & 0,21 & 0,02 & $0,21-0,02 \mu$ & 9,98 & 11,03 & 1,05 & $11,03-1,05 \mu$ & 0,06 & 0,07 & 0,01 & $0,06+0,01 \mu$ \\
\hline $\mathrm{I}_{\mathbf{I}}$ & 479,75 & 530,25 & 50,50 & $530,25-50,5 \mu$ & 18,43 & 20,37 & 1,94 & $20,37-1,94 \mu$ & 0,19 & 0,21 & 0,02 & $0,21-0,02 \mu$ & 0,38 & 0,42 & 0,04 & $0,42-0,04 \mu$ & 0,41 & 0,45 & 0,04 & $0,41+0,04 \mu$ \\
\hline $\mathbf{I}_{15}$ & 336,30 & 371,70 & 35,40 & $371,7-35,4 \mu$ & 10,17 & 11,24 & 1,07 & $11,24-1,07 \mu$ & 0,10 & 0,11 & 0,01 & $0,11-0,01 \mu$ & 0 & 0 & 0 & 0 & 0,2 & 0,22 & 0,02 & $0,2+0,02 \mu$ \\
\hline$\dot{\mathbf{I}} \mathbf{G}_{16}$ & 399,95 & 442,05 & 42,10 & $442,05-42,1 \mu$ & 14,25 & 15,75 & 1,50 & $15,75-1,5 \mu$ & 0,29 & 0,32 & 0,03 & $0,32-0,03 \mu$ & 3,14 & 3,47 & 0,33 & $3,47-0,33 \mu$ & 0,58 & 0,64 & 0,06 & $0,58+0,06 \mu$ \\
\hline $\mathbf{I} \mathbf{G}_{17}$ & 278,45 & \begin{tabular}{|l|}
307,76 \\
\end{tabular} & 29,31 & $307,76-29,31 \mu$ & 8,93 & 9,87 & 0,94 & $9,87-0,94 \mu$ & 0,10 & 0,11 & 0,01 & $0,11-0,01 \mu$ & 6,37 & 7,04 & 0,67 & $7,04-0,67 \mu$ & 0,23 & 0,25 & 0,02 & $0,23+0,02 \mu$ \\
\hline$\dot{\mathbf{I}} \mathbf{G}_{18}$ & 350,08 & \begin{tabular}{|l|}
386,93 \\
\end{tabular} & 36,85 & $386,93-36,85 \mu$ & 10,55 & 11,66 & 1,11 & $11,66-1,11 \mu$ & 0,10 & 0,11 & 0,01 & $0,11-0,01 \mu$ & 21,28 & 23,52 & 2,24 & $23,52-2,24 \mu$ & 0,31 & 0,34 & 0,03 & $0,31+0,03 \mu$ \\
\hline$\ddot{\mathbf{U}} \mathbf{G}_{1}$ & 329,65 & 364,35 & 34,70 & $364,35-34,7 \mu$ & 7,98 & 8,82 & 0,84 & $8,82-0,84 \mu$ & 0,10 & 0,11 & 0,01 & $0,11-0,01 \mu$ & 2,09 & 2,31 & 0,22 & $2,31-0,22 \mu$ & 0,35 & 0,39 & 0,04 & $0,35+0,04 \mu$ \\
\hline$\ddot{\mathbf{U}} \mathbf{G}_{2}$ & 486,69 & 537,92 & 51,23 & $537,92-51,23 \mu$ & 4,09 & 4,52 & 0,43 & $4,52-0,43 \mu$ & 0 & 0 & 0 & 0 & 0,19 & 0,21 & 0,02 & $0,21-0,02 \mu$ & 0,21 & 0,23 & 0,02 & $0,02 \mu$ \\
\hline$\ddot{U} \mathbf{G}_{3}$ & \begin{tabular}{|l|l|}
458,47 \\
\end{tabular} & \begin{tabular}{|l|}
506,73 \\
\end{tabular} & 48,26 & $506,73-48,26 \mu$ & 4,75 & 5,25 & 0,50 & $5,25-0,5 \mu$ & 0 & 0 & 0 & 0 & 0,19 & 0,21 & 0,02 & $0,21-0,02 \mu$ & 0,2 & 0,23 & 0,02 & $0,02 \mu$ \\
\hline$\ddot{\mathbf{U}} \mathbf{G}_{4}$ & 349,22 & 385,98 & 36,76 & $385,98-36,76 \mu$ & 4,56 & 5,04 & 0,48 & $5,04-0,48 \mu$ & 0 & 0 & 0 & 0 & 0,19 & 0,21 & 0,02 & $0,21-0,02 \mu$ & 0,2 & 0,22 & 0,02 & $0,02 \mu$ \\
\hline$\ddot{\mathbf{U}} \mathbf{G}_{5}$ & 116,85 & 129,15 & 12,30 & $129,15-12,3 \mu$ & 1,24 & 1,37 & 0,13 & $1,365-0,13 \mu$ & 0,10 & 0,11 & 0,01 & $0,11-0,01 \mu$ & 27,36 & 30,24 & 2,88 & $30,24-2,88 \mu$ & 0,26 & 0,29 & 0,03 & $0,26+0,03 \mu$ \\
\hline$\ddot{\mathbf{U}} \mathbf{G}_{6}$ & 79,80 & 88,20 & 8,40 & $88,2-8,4 \mu$ & 0,86 & 0,95 & 0,10 & $0,95-0,09 \mu$ & 0,10 & 0,11 & 0,01 & $0,11-0,01 \mu$ & 10,07 & 11,13 & 1,06 & $11,13-1,06 \mu$ & 0,23 & 0,25 & 0,02 & $0,23+0,02 \mu$ \\
\hline $\mathbb{U}_{\mathbf{G}} \mathbf{G}_{7}$ & \begin{tabular}{|l|}
107,35 \\
\end{tabular} & 118,65 & 11,30 & $118,65-11,3 \mu$ & 1,71 & 1,89 & 0,18 & $1,89-0,18 \mu$ & 0,10 & 0,11 & 0,01 & $0,11-0,01 \mu$ & 49,59 & 54,81 & 5,22 & $54,81-5,22 \mu$ & 0,29 & 0,32 & 0,03 & $0,29+0,03 \mu$ \\
\hline ÜG 8 & \begin{tabular}{|l|}
175,66 \\
\end{tabular} & 194,15 & 18,49 & $194,15-18,49 \mu$ & 3,61 & 3,99 & 0,38 & $3,99-0,38 \mu$ & 0,19 & 0,21 & 0,02 & $0,21-0,02 \mu$ & 60,33 & 66,68 & 6,35 & $66,68-6,35 \mu$ & 0,25 & 0,27 & 0,03 & $0,25+0,03 \mu$ \\
\hline ÜG9 & 95,95 & 106,05 & 10,10 & $106,05-10,1 \mu$ & 0,48 & 0,53 & 0,05 & $0,53-0,05 \mu$ & 0 & 0 & 0 & 0 & 9,5 & 10,5 & 1 & $10,5-1 \mu$ & 0,27 & 0,3 & 0,03 & $7+0,03 \mu$ \\
\hline $\mathbf{U ̈ G}_{\mathbf{1 0}}$ & 68,40 & 75,60 & 7,20 & $2 \mu$ & 0,86 & 0,95 & 0,09 & $9 \mu$ & 0 & 0 & 0 & 0 & 10,45 & 11,55 & 1,1 & $1,55-1,1 \mu$ & 0,26 & 0,28 & 0,03 &, $03 \mu$ \\
\hline ÜG $\mathbf{G}_{11}$ & 145,64 & 160,97 & 15,33 & $160,97-15,33 \mu$ & 1,71 & 1,89 & 0,1 & $1,89-0,18 \mu$ & 0 & 0 & 0 & 0 & 13,11 & 14,49 & 1,38 & $14,49-1,38 \mu$ & 0,5 & 0,56 & 0,05 & $0,05 \mu$ \\
\hline$\ddot{\mathbf{U}} \mathbf{G}_{12}$ & 59,85 & 66,15 & 6,30 & $66,15-6,3 \mu$ & 1,52 & 1,68 & 0,1 & $1,68-0,16 \mu$ & 0 & 0 & 0 & 0 & 13,3 & 14,7 & 1,4 & $14,7-1,4 \mu$ & 0,39 & 0,43 & 0,04 & $39+0,04 \mu$ \\
\hline$\ddot{\mathbf{U}} \mathbf{G}_{13}$ & 102,60 & 113,40 & 10,80 & $113,4-10,8 \mu$ & 0,86 & 0,95 & 0,09 & $0,95-0,09 \mu$ & 0,10 & 0,11 & 0,01 & $0,11-0,01 \mu$ & 3,8 & 4,2 & 0,4 & $4,2-0,4 \mu$ & 0,29 & 0,32 & 0,03 & $0,29+0,03 \mu$ \\
\hline $\mathbf{U}_{\mathbf{H}}$ & 73,15 & 80,85 & 7,70 & $80,85-7,7 \mu$ & 1,33 & 1,47 & 0,14 & $1,47-0,14 \mu$ & \begin{tabular}{|l|}
0,095 \\
\end{tabular} & 0,105 & 0,01 & $0,105-0,01 \mu$ & 76 & 84 & 8 & $84-8 \mu$ & 0,22 & 0,24 & 0,02 & $0,22+0,02 \mu$ \\
\hline ÜG $\mathbf{G}_{15}$ & 69,35 & 76,65 & 7,30 & $76,65-7,3 \mu$ & 1,24 & 1,37 & 0,13 & $1,37-0,13 \mu$ & 0,095 & 0,105 & 0,01 & $0,105-0,01 \mu$ & 14,25 & 15,75 & 1,5 & $15,75-1,5 \mu$ & 0,17 & 0,18 & 0,02 & $0,17+0,02 \mu$ \\
\hline $\mathbf{U G}_{16}$ & 65,55 & 72,45 & 6,90 & $72,45-6,9 \mu$ & 1,05 & 1,16 & 0,11 & $1,16-0,11 \mu$ & \begin{tabular}{|l|}
0,095 \\
\end{tabular} & 0,105 & 0,01 & $0,105-0,01 \mu$ & 78,85 & 87,15 & 8,3 & $87,15-8,3 \mu$ & 0,18 & 0,2 & 0,02 & $18+0,02 \mu$ \\
\hline $\mathbf{U}_{\mathbf{1 7}}$ & 66,50 & 73,50 & 7,00 & $73,5-7 \mu$ & 0,95 & 1,05 & 0,1 & $1,05-0,1 \mu$ & 0,095 & 0,105 & 0,01 & $0,105-0,01 \mu$ & 43,7 & 48,3 & 4,6 & $48,3-4,6 \mu$ & 0,23 & 0,25 & 0,02 & $23+0,02 \mu$ \\
\hline$\ddot{\mathbf{U}} \mathbf{G}_{18}$ & 78,85 & 87,15 & 8,30 & $, 15-8,3 \mu$ & 1,05 & 1,16 & 0,1 & $1,16-0,11 \mu$ & 0 & 0 & 0 & $0-0 \mu$ & 37,05 & 40,95 & 3,9 & $40,95-3,9 \mu$ & 0,23 & 0,26 & 0,02 & $0,02 \mu$ \\
\hline$\ddot{\mathbf{U}} \mathbf{G}_{19}$ & 107,35 & 118,65 & 11,30 & $118,65-11,3 \mu$ & 48 & 0,53 & 0,0 & $0,53-0,05 \mu$ & 0 & $\underline{0}$ & 0 & $0-0 \mu$ & 9,5 & 10,5 & 1 & $10,5-1 \mu$ & 0,24 & 0,26 & 0,02 & $, 24+0,02 \mu$ \\
\hline$\ddot{\mathbf{U}} \mathbf{G}_{20}$ & 54,15 & 59,85 & 5,70 & $59,85-5,7 \mu$ & 1,05 & 1,16 & 0,11 & $1,16-0,11 \mu$ & 0 & 0 & 0 & $0-0 \mu$ & 95 & 105 & 10 & $105-10 \mu$ & 0,17 & 0,19 & 0,02 & $0,17+0,02 \mu$ \\
\hline$\ddot{\mathbf{U}} \mathbf{G}_{21}$ & 56,05 & 61,95 & 5,90 & $61,95-5,9 \mu$ & 0,67 & 0,74 & 0,07 & $0,74-0,07 \mu$ & 0 & 0 & 0 & $0-0 \mu$ & 8,55 & 9,45 & \begin{tabular}{l|}
0,9 \\
\end{tabular} & $9,45-0,9 \mu$ & 0,18 & 0,2 & 0,02 & $0,18+0,02 \mu$ \\
\hline $\mathbf{U}_{\mathbf{G}}$ & 42,75 & 47,25 & 4,50 & $47,25-4,5 \mu$ & 2,47 & 2,73 & 0,26 & $2,73-0,26 \mu$ & 0 & $\underline{0}$ & 0 & $0-0 \mu$ & 0 & 0 & 0 & 0 & 0,24 & 0,26 & 0,03 & $0,24+0,03 \mu$ \\
\hline$\ddot{\mathbf{U}} \mathbf{G}_{23}$ & 184,30 & \begin{tabular}{|l|}
203,70 \\
\end{tabular} & 19,40 & $203,7-19,4 \mu$ & 10,03 & 11,09 & 1,06 & $11,09-1,06 \mu$ & 0,19 & 0,21 & 0,02 & $0,21-0,02 \mu$ & 2,85 & 3,15 & 0,3 & $3,15-0,3 \mu$ & 0,31 & 0,35 & 0,03 & $0,31+0,03 \mu$ \\
\hline $\mathbf{U G}_{24}$ & 9,50 & 10,50 & \begin{tabular}{|l|} 
\\
\end{tabular} & $10,5-1 \mu$ & 0,57 & 0,63 & 0,06 & $0,63-0,06 \mu$ & 0 & 0 & 0 & $0-0 \mu$ & 0,67 & 0,74 & 0,07 & $0,74-0,07 \mu$ & 0,46 & 0,5 & 0,05 & $0,46+0,05 \mu$ \\
\hline
\end{tabular}


Tablo 4.Üyelik Derecelerine Göre Menüler

\begin{tabular}{|c|c|c|c|c|c|c|}
\hline $\mathbf{j}$ & $\boldsymbol{\mu}=\mathbf{0}$ & S. D. & $\mu=0.5$ & S. D. & $\mu=1$ & S. D. \\
\hline \multirow{4}{*}{$\begin{array}{l}1 . \\
\text { Gün }\end{array}$} & Kıymalı Karnabahar & $\mathrm{e}^{+}=24,6$ & Un Çorbası & $\mathrm{e}^{+}=7,6$ & Şehriye Çorbası & $\mathrm{e}^{+}=1$ \\
\hline & Firında Makarna & $\mathrm{cv}^{+}=96,22$ & $\begin{array}{l}\text { Alabalık Tava (Sebze } \\
\text { G.) }\end{array}$ & $\mathrm{cv}^{+}=9,6$ & \begin{tabular}{|c|} 
Rosto Et (Patates \\
G.) \\
\end{tabular} & $\mathrm{cv}^{+}=29,94$ \\
\hline & Turşu & $\mathrm{p}^{+}=11,29$ & Kivircik Salata & $\mathrm{p}^{+}=33,29$ & Zeytinyağlı Bakla & $p^{+}=6,56$ \\
\hline & & $\mathrm{t}^{+}=0,06$ & & $\mathrm{t}^{+}=0,12$ & Elma & $\mathrm{t}^{+}=0,17$ \\
\hline \multirow{4}{*}{$\begin{array}{l}2 . \\
\text { Gün }\end{array}$} & Şehriye Çorbas 1 & $e^{-}=1,2$ & Etli Kabak Dolması & $e^{-}=10$ & Yayla Çorbas1 & $\mathrm{e}^{+}=19,33$ \\
\hline & $\begin{array}{c}\text { Alabalık Tava (Sebze } \\
\text { G.) }\end{array}$ & $\mathrm{cv}^{+}=18,41$ & Tepsi Böreği & $\mathrm{Cv}^{+}=2$ & $\begin{array}{l}\text { Kiymalı Taze } \\
\text { Fasulye }\end{array}$ & $\mathrm{cv}^{+}=4,01$ \\
\hline & Karpuz & $\mathrm{p}^{+}=36,6$ & Kayis1 & $\mathrm{p}^{+}=4,29$ & Tepsi Böreği & $\mathrm{p}=6,07$ \\
\hline & & $\mathrm{t}^{+}=0,06$ & & $\mathrm{t}^{+}=0,02$ & & $t=0,115$ \\
\hline \multirow{4}{*}{$\begin{array}{l}\text { 3. } \\
\text { Gün }\end{array}$} & \begin{tabular}{|c|}
$\begin{array}{c}\text { Söğüş Et (Patates Püre } \\
\text { G.) }\end{array}$ \\
\end{tabular} & $\mathrm{e}^{+}=2,55$ & Şehriye Çorbası & $\mathrm{e}^{+}=8,6$ & \begin{tabular}{|c} 
Söğüş Et (P. Püre \\
G.)
\end{tabular} & $\mathrm{e}^{+}=14,3$ \\
\hline & Z. Biber Dolmas1 & $\mathrm{cv}^{+}=157,9$ & Kiymalı Ispanak & $\mathrm{cv}^{+}=44,3$ & Tepsi Böreği & $c v^{-}=10,71$ \\
\hline & Kavun & $\mathrm{p}^{+}=5,31$ & Revani & $p^{-}=0,51$ & Kivircik Salata & $\mathrm{p}^{+}=9,885$ \\
\hline & & $t^{2}=0,045$ & & $t=0,18$ & & $t^{+}=0,075$ \\
\hline \multirow{4}{*}{$\begin{array}{c}4 . \\
\text { Gün }\end{array}$} & Kıymalı Ispanak & $e^{-}=1,54$ & Yayla Çorbası & $\mathrm{e}^{+}=37,6$ & $\begin{array}{c}\text { Piliç Şnitzel (Sebze } \\
\text { G.) }\end{array}$ & $e^{-}=18,76$ \\
\hline & Su Böreği & $\mathrm{cv}^{+}=60,62$ & Kiymalı Kapuska & $\mathrm{cv}^{+}=32,3$ & Z. Biber Dolmas1 & $\mathrm{cv}^{+}=66,52$ \\
\hline & Üzüm & $\mathrm{p}^{+}=5,65$ & Sekerpare & $\mathrm{p}=4,11$ & Turşu & $\mathrm{p}^{+}=33,065$ \\
\hline & & $\mathrm{t}^{+}=0,06$ & & $t=0,18$ & & $t=0,02$ \\
\hline \multirow{4}{*}{$\begin{array}{l}5 . \\
\text { Gün }\end{array}$} & Domates Çorbası & $\mathrm{e}^{+}=14,73$ & Karnıyarık & $\mathrm{e}^{+}=7,1$ & Dana Haşlama & $\mathrm{e}^{-}=10,02$ \\
\hline & Piliç Izgara (Sebze G.) & $\mathrm{cv}^{-}=8,46$ & Su Böreği & $c v=5,5$ & Pirinç Pilav1 & $\mathrm{cv}^{+}=22,25$ \\
\hline & Yoğurt & $\mathrm{p}^{+}=43,27$ & Yoğurt & $\mathrm{p}^{+}=6,85$ & Çoban Salata & $\mathrm{p}^{+}=17,105$ \\
\hline & & $\mathrm{t}^{+}=0,165$ & & $\mathrm{t}^{+}=0,02$ & & $t=0,115$ \\
\hline \multirow{4}{*}{$\begin{array}{l}\text { 6. } \\
\text { Gün }\end{array}$} & $\begin{array}{l}\text { S. Soslu Tavuk (P. } \\
\text { Pilavı G.) }\end{array}$ & 35,2 & $\begin{array}{l}\text { Kuzu Fırın (Pirinç } \\
\text { Pilavı G.) }\end{array}$ & $e^{-}=3,1$ & Un Çorbası & $e^{-}=1$ \\
\hline & Zeytinyağlı Barbunya & $\mathrm{cv}^{+}=65,45$ & Z. Taze Fasulye & $\mathrm{cv}^{+}=18,1$ & Kiymalı Ispanak & $c v^{+}=38,4$ \\
\hline & Portakal & $\mathrm{p}^{+}=35,44$ & Muz & $\mathrm{p}^{+}=25,59$ & Revani & $\mathrm{p}=1,8$ \\
\hline & & $\mathrm{t}^{+}=0,06$ & & $t=0,08$ & & $t=0,115$ \\
\hline \multirow{4}{*}{$\begin{array}{l}7 . \\
\text { Gün }\end{array}$} & \begin{tabular}{|c} 
Firın Köfte (Patates Püre \\
G.)
\end{tabular} & $\mathrm{e}^{-}=0,6$ & $\begin{array}{l}\text { Soya Soslu Tavuk } \\
\text { (Pirinç Pilavı G.) }\end{array}$ & $\mathrm{e}^{+}=6,1$ & $\begin{array}{l}\text { Kadınbudu Köfte } \\
\text { (Patates Püre G.) }\end{array}$ & $e^{+}=1$ \\
\hline & Z. Yaprak Dolması & $\mathrm{cv}^{+}=38,36$ & Z. Barbunya & $\mathrm{cv}^{-}=13,9$ & Peynirli Makarna & $\mathrm{cV}^{-}=12,71$ \\
\hline & Elma & $\mathrm{p}^{+}=0,06$ & Armut & $\mathrm{p}^{+}=30,99$ & Erik & $\mathrm{p}^{+}=2,38$ \\
\hline & & $t^{\prime}=0,045$ & & $t=0,08$ & & $t=0,115$ \\
\hline \multirow{4}{*}{$\begin{array}{l}8 . \\
\text { Gün }\end{array}$} & Etli Kabak Dolmas 1 & $e^{-}=0,07$ & Piliç Izgara (Sebze G.) & $\mathrm{e}^{+}=4,6$ & Etli Nohut & $\mathrm{e}^{+}=2,45$ \\
\hline & Ispanaklı Börek & $\mathrm{cv}^{+}=28,7$ & Peynirli Makarna & $c v=1,6$ & Ispanaklı Börek & $c v^{\prime}=2,73$ \\
\hline & Kiraz & $\mathrm{p}^{+}=3,42$ & Kiraz & $\mathrm{p}^{+}=37,39$ & Armut & $\mathrm{p}^{+}=3,71$ \\
\hline & & $t=0,15$ & & $t^{-}=0,08$ & & $t=0,02$ \\
\hline \multirow{4}{*}{$\begin{array}{c}9 . \\
\text { Gün }\end{array}$} & Şehriye Çorbası & $\mathrm{e}^{+}=5,7$ & Etli Kuru Fasulye & $e^{+}=5$ & Domates Çorbas1 & $e^{+}=4,42$ \\
\hline & Kiymalı Taze Fasulye & $\mathrm{cv}^{+}=13,69$ & Pirinç Pilavı & $\mathrm{cv}^{+}=8,3$ & Kıymalı Kapuska & $\mathrm{cv}^{+}=28,23$ \\
\hline & Sütlaç & $\mathrm{p}^{+}=0,79$ & Şeftali & $\mathrm{p}^{+}=2,19$ & Şekerpare & $\mathrm{p}=6,07$ \\
\hline & & $t=0,045$ & & $\mathrm{t}^{+}=0,02$ & & $t=0,21$ \\
\hline \multirow{4}{*}{$\begin{array}{c}10 . \\
\text { Gün }\end{array}$} & Yayla Çorbas1 & $e^{-}=6,27$ & Domates Çorbası & $e^{e}=3$ & Etli Türlü & $\mathrm{e}^{+}=6,7$ \\
\hline & Kiymalı Kapuska & $\mathrm{cv}^{+}=37,31$ & Haşlama Tavuk & $\mathrm{cv}^{+}=33$ & Tepsi Böreği & $\mathrm{cv}^{+}=0,4$ \\
\hline & Revani & $\mathrm{p}=2,25$ & Z. Yaprak Dolmas1 & $\mathrm{p}^{+}=12,29$ & Yoğurt & $\mathrm{p}^{+}=10,03$ \\
\hline & & $\mathrm{t}=0,15$ & Erik & $\mathrm{t}^{+}=0,02$ & & $\mathrm{t}^{+}=0,17$ \\
\hline
\end{tabular}




\begin{tabular}{|c|c|c|c|c|c|c|}
\hline $\mathbf{j}$ & $\mu=0$ & S. D. & $\mu=0.5$ & S. D. & $\mu=1$ & S. D. \\
\hline \multirow{4}{*}{$\begin{array}{l}11 . \\
\text { Gün }\end{array}$} & Dana Haşlama & $\mathrm{e}^{-}=2,28$ & Şehriye Çorbası & $\mathrm{e}^{+}=12,2$ & Şehriye Çorbası & $\mathrm{e}^{-}=3,75$ \\
\hline & İmambayıld1 & $\mathrm{cv}^{+}=6,654$ & Piliç Şnitzel (Sebze G.) & $\mathrm{cv}^{+}=36,6$ & Etli Kuru Fasulye & $\mathrm{cv}^{+}=14,74$ \\
\hline & Armut & $\mathrm{p}^{+}=19,59$ & Çoban Salata & $\mathrm{p}^{+}=35,59$ & Bulgur Pilavi & $\mathrm{p}^{+}=3,23$ \\
\hline & & $t=0,15$ & & $\mathrm{t}^{+}=0,02$ & Şeftali & $\mathrm{t}^{+}=0,075$ \\
\hline \multirow{4}{*}{$\begin{array}{l}12 . \\
\text { Gün }\end{array}$} & Etli Türlü & $\mathrm{e}^{+}=8,85$ & Dana Haşlama & $e=6,6$ & Etli Kabak Dolması & $e^{-}=3,75$ \\
\hline & Tepsi Böreği & $\mathrm{cv}^{+}=4,45$ & Zeytinyağlı Bakla & $\mathrm{cv}^{+}=25,3$ & Firında Makarna & $\mathrm{cv}^{-}=12,04$ \\
\hline & Ayran & $\mathrm{p}^{+}=7,51$ & Uzüm & $\mathrm{p}^{+}=26,09$ & Karpuz & $\mathrm{p}^{+}=6,37$ \\
\hline & & $\mathrm{t}^{+}=0,06$ & & $\mathrm{t}^{+}=0,32$ & & $t^{\prime}=0,02$ \\
\hline \multirow{4}{*}{$\begin{array}{l}13 . \\
\text { Gün }\end{array}$} & İzmir Köfte & $\mathrm{e}^{+}=2,55$ & Yayla Çorbası & $\mathrm{e}^{+}=8$ & $\begin{array}{l}\text { K. Mercimek } \\
\text { Corbas1 }\end{array}$ & $\mathrm{e}^{-}=10,3$ \\
\hline & Zeytinyağlı Bakla & $\mathrm{cv}^{+}=42,88$ & Rosto Et (Patates G.) & $\mathrm{cv}^{+}=6,9$ & Karnıyarık & $\mathrm{cv}^{+}=4,86$ \\
\hline & Kayıs1 & $p^{+}=6,57$ & İmambayıldı & $\mathrm{p}^{+}=1,59$ & Su Böreği & $\mathrm{p}^{+}=2,57$ \\
\hline & & $\mathrm{t}^{+}=0,37$ & Elma & $t=0,08$ & Kayısis & $\mathrm{t}^{-}=0,02$ \\
\hline \multirow{4}{*}{$\begin{array}{l}14 . \\
\text { Gün }\end{array}$} & Karnıyarık & $\mathrm{e}^{+}=4,65$ & Söğüş Et (P.Püre G.) & $\mathrm{e}^{+}=3$ & İzmir Köfte & $e^{-}=8,5$ \\
\hline & Peynirli Makarna & $\mathrm{cv}^{+}=1,09$ & Bulgur Pilavi & $\mathrm{cv}^{+}=17,7$ & Peynirli Makarna & $\mathrm{cv}^{+}=5,05$ \\
\hline & Erik & $\mathrm{p}^{+}=0,48$ & Kivircık Salata & $\mathrm{p}^{+}=4,69$ & Kıvircık Salata & $\mathrm{p}^{+}=1,43$ \\
\hline & & $t=0,15$ & & $\mathrm{t}^{+}=0,02$ & & $\mathrm{t}=0,02$ \\
\hline \multirow{4}{*}{$\begin{array}{l}15 . \\
\text { Gün }\end{array}$} & Haşlama Tavuk & $\mathrm{e}^{+}=0,45$ & $\begin{array}{c}\text { Kırmızı Mercimek } \\
\text { Çorbas1 }\end{array}$ & $\mathrm{e}^{+}=1$ & Domates Çorbası & $\mathrm{e}^{+}=5,37$ \\
\hline & Pirinç Pilavı & $\mathrm{cv}^{-}=5,84$ & Etli Türlü & $\mathrm{cv}^{+}=2,1$ & $\begin{array}{c}\text { Kuzu Firın (P. Pilav } \\
\text { G.) }\end{array}$ & $\mathrm{cv}^{-}=3,49$ \\
\hline & Kivircik Salata & $\mathrm{p}^{+}=11,82$ & Sütlaç & $p^{+}=3,69$ & Imambayild 1 & $\mathrm{p}^{+}=23,75$ \\
\hline & & $t^{t}=0,06$ & & $\mathrm{t}^{+}=0,02$ & Kiraz & $\mathrm{t}=0,02$ \\
\hline \multirow{4}{*}{$\begin{array}{l}\text { 16. } \\
\text { Gün }\end{array}$} & Un Çorbası & $e^{-}=24,75$ & Kıymalı Taze Fasulye & $e^{e}=13$ & $\begin{array}{c}\text { Firın Köfte (P. Püre } \\
\text { G.) }\end{array}$ & $e^{+}=3,85$ \\
\hline & Rosto Et (Patates G.) & $\mathrm{cv}^{+}=10,85$ & Firında Makarna & $\mathrm{cv}^{+}=8,4$ & Z. Taze Fasulye & $\mathrm{cv}^{+}=16,93$ \\
\hline & Karışık Salata & $p^{+}=2,05$ & Turşu & $\mathrm{p}^{+}=8,39$ & Sütlaç & $\mathrm{p}^{+}=2,09$ \\
\hline & & $\mathrm{t}=0,045$ & & $\mathrm{t}^{+}=0,02$ & & $\mathrm{t}^{-}=0,02$ \\
\hline \multirow{4}{*}{$\begin{array}{l}\text { 17. } \\
\text { Gün }\end{array}$} & Etli Kuru Fasulye & $\mathrm{e}^{+}=19,35$ & $\begin{array}{c}\text { K.budu Köfte (P. Püre } \\
\text { G.) }\end{array}$ & $\mathrm{e}^{+}=5$ & Un Çorbası & $e^{-}=9,45$ \\
\hline & Bulgur Pilav1 & $\mathrm{cv}^{+}=30,49$ & Z. Biber Dolmasi & $\mathrm{cv}^{+}=85$ & Haşlama Tavuk & $\mathrm{cv}^{+}=21,96$ \\
\hline & Mandalina & $p^{+}=6,36$ & Karpuz & $p^{-}=0,61$ & Z. Yaprak Dolmas1 & $p^{+}=9,03$ \\
\hline & & $\mathrm{t}^{+}=0,27$ & & $t^{+}=0,02$ & Üzüm & $\mathrm{t}^{+}=0,075$ \\
\hline \multirow{4}{*}{$\begin{array}{l}18 . \\
\text { Gün }\end{array}$} & $\begin{array}{c}\text { Kadınbudu Köfte (P. } \\
\text { Püre G.) }\end{array}$ & $\mathrm{e}^{-}=1,65$ & $\begin{array}{c}\text { Firın Köfte (Patates } \\
\text { Püre G.) }\end{array}$ & $e^{e}=10$ & $\begin{array}{c}\text { Piliç Izgara (Sebze } \\
\text { G.) }\end{array}$ & $e^{-}=1,94$ \\
\hline & Z. Taze Fasulye & $\mathrm{cv}^{+}=64,51$ & Peynirli Makarna & $\mathrm{cv}^{+}=61,2$ & Pirinç Pilavi & $\mathrm{cv}^{-}=5,11$ \\
\hline & Şeftali & $\mathrm{p}^{+}=0,27$ & Kavun & $\mathrm{p}^{+}=4,79$ & Muz & $\mathrm{p}^{+}=27,74$ \\
\hline & & $t=0,045$ & & $\mathrm{t}^{+}=0,02$ & & $\mathrm{t}^{-}=0,115$ \\
\hline \multirow{4}{*}{$\begin{array}{l}19 . \\
\text { Gün }\end{array}$} & $\begin{array}{c}\text { Kırmızı Mercimek } \\
\text { Çorbası }\end{array}$ & $\mathrm{e}^{+}=8,11$ & Etli Nohut & $\mathrm{e}^{+}=6$ & $\begin{array}{l}\text { Alabalık Tava } \\
\text { (Sebze G.) }\end{array}$ & $\mathrm{e}^{-}=1,18$ \\
\hline & Etli Nohut & $\mathrm{cv}^{-}=13,08$ & Pirinç Pilav1 & $\mathrm{cv}^{+}=14,3$ & Su Böreği & $\mathrm{cv}^{+}=2,01$ \\
\hline & Muz & $p^{+}=6,88$ & Mandalina & $\mathrm{p}^{+}=0,39$ & Ayran & $\mathrm{p}^{+}=37,24$ \\
\hline & & $\mathrm{t}^{+}=0,165$ & & $\mathrm{t}^{+}=0,12$ & & $\mathrm{t}^{-}=0,02$ \\
\hline \multirow{4}{*}{\begin{tabular}{|l}
20. \\
Gün
\end{tabular}} & Domates Çorbası & $\mathrm{e}^{+}=12,63$ & İzmir Köfte & $\mathrm{e}^{+}=6,5$ & Sehriye Corbas1 & $e^{-}=0,8$ \\
\hline & Kuzu Firın (P. Pilav G.) & $\mathrm{cv}^{+}=24,19$ & Ispanaklı Börek & $\mathrm{cv}^{+}=2,5$ & $\begin{array}{c}\text { S.Soslu Tavuk (P. } \\
\text { P. G.) }\end{array}$ & $\mathrm{cv}^{+}=17,88$ \\
\hline & Çoban Salata & $\mathrm{p}^{+}=29,04$ & Ayran & $p^{+}=5,59$ & Mandalina & $\mathrm{p}^{+}=29,36$ \\
\hline & & $\mathrm{t}^{\mathrm{t}}=0,06$ & & $\mathrm{t}^{\mathrm{t}}=0,08$ & & $\mathrm{t}^{-}=0,02$ \\
\hline
\end{tabular}




\section{KAYNAKÇA}

Abdel Kader, M.G. ve Dugdale, D. (2001), "Evaluating Investment in Advanced Manufacturing Technology: A Fuzzy Set Theory Approach”, British Accounting Review, 33: 455-489.

Balintfy, J.L., Ross, G.T., Sinha P. ve Zoltners, A.A. (1978), “A Mathematical Programming Systems For Preference and Compability Maximized Menu Planning and Scheduling", Mathematical Programming, 15: 63-76.

Baykal, N. ve Beyan, T. (2004),“Bulanık Mantık İlke ve Temelleri”, Ankara: Bıçaklar Kitabevi.

Beyhan, Y., ve Ciğerim, N. (1995),“Toplu Beslenme Sistemlerinde Menü Yönetimi ve Denetimi”, Ankara: Kök Yayıncılık.

Carlsson, C. ve Korhonen, P. (1986), “A Parametric Approach to Fuzzy Linear Programming”, Fuzzy Sets and Systems, 20: 17-30.

Chen, H. (1994), “A Note on a Fuzzy Goal Programming Algorithm by Tiwari, Dharmar, and Rao", Fuzzy Sets and Systems, 62: 287-290.

Demirci, M. (2003),“Beslenme”, Tekirdağ: Rebel Yayıncılık.

Ediz, A. ve Yağdıran, Y. (2009), "Hedef Programlama Tekniği ile Menü Planlaması”, Gazi Üniversitesi İktisadi ve İdari Bilimler Fakültesi Dergisi, 11 (1): 45-74.

Eraslan, M., Gülegül, H.İ., Sunar, F., Uygur, F., Panal, A., ve Konakoğlu, S. (2003), “Toplu Beslenme Sektörü Araştırması (Merkez Mutfaklar)”,Ankara: MEB Mesleki ve Teknik Eğitim Araştırma ve Geliştirme Merkezi Başkanlığı Yayını.

Günyaşar, V. ve Oral, H. (2005), "Menü Planlamasında Çok Amaçlı Programlama Yaklaşımı", Marmara Üniversitesi Sosyal Bilimler Enstitüsü Dergisi, 23: 119-127.

Hannan, E. L. (1981), “On Fuzzy Goal Programming”, Decision Analysis, 12: 523-531.

Kırılmaz, A.Ö. (2008), “Ankara Üniversitesi Toplu Beslenme Servislerinde Çalı̧̧an Personele Verilecek Hijyen/Sanitasyon Paket Eğitim Programlarının Değerlendirilmesi”,Yüksek Lisans Tezi, Hacettepe Üniversitesi, Sağlık Bilimler Enstitüsü, Ankara.

Kim, J.S. ve Whang, K. S. (1998), “A Tolerance Appoach to the Fuzzy Goal Programming Problems with Unbalanced Triangular Membership Function", European Journal of Operational Research, 107: 617-624.

Mamat, M., Rokhayati, Y., Noor, M. M. ve Mohd İ. (2011), "Optimizing Human Diet Problem with Fuzzy Price Using Fuzzy Linear Programming Approach”, Pakistan Journal of Nutrition, 10 (6): 594-598. 
Mamat, M., Zulkifli, N.F., Deraman, S.K., ve Noor, M. M. (2012), "Fuzzy Linear Programming Approach in Balance Diet Planning for Eating Disorder and Disease-related Lifestyle", Applied Mathematical Sciences, 6 (103): 5109-5118.

Narasimhan, R. (1980), “Goal Programming in a Fuzzy Environment”, Decision Analysis, 11: 325336.

Oruç, K. O., Güngör, İ., Irmak, S. ve Şenol, S. (2012), "Menu Planning with Fuzzy 0-1 Integer Programming”, International Burch University 3rd International Symposium on Sustainable Development, Bildiriler Kitabi: 6-27.

Özkan, M. (2003),“Bulanık Hedef Programlama”, Bursa: Ekin Yayınevi.

Öztürk, A. (2009),“Yöneylem Araştırması”, 12. Bask1, Bursa: Ekin Yayınevi.

Sklan, D. ve Dariel, I. (1993), "Diet Planning for Humans Using Mixed-Integer Linear Programming”, British Journal of Nutrition, 70: 27-35.

Soden, P.M. ve Fletcer, L.R. (1992), "Modifying Diets to Satisfy Nutritional Requirements Using Linear Programming”, British Journal of Nutrition, 68: 565-572.

Şenol, S. (2011), "Menü Planlama Sorununa Karma Tamsayılı Programlama Modeli İle Çözüm Önerisi”, Yüksek Lisans Tezi, Süleyman Demirel Üniversitesi, Sosyal Bilimler Enstitüsü, Isparta.

Taha, H.A. (2009), “Yöneylem Araştırması”, 6. Basımdan Çeviri, İstanbul: Literatür Yayıncılık.

Tiwari, R.N., Dharmar, S. ve Rao, J.R. (1986), "Priority Structure in Fuzzy Goal Programming", Fuzzy Sets and Systems, 19: 251-259.

Tümer, H. (2008), “Toplu Beslenme Hizmeti Verilen Kurumlarda Mutfak Planının İncelenmesi ve Mutfak Planının İş Akışına Etkisi Üzerine Bir Araştırma”,Yüksek Lisans Tezi, Hacettepe Üniversitesi, Sağlık Bilimleri Enstitüsü, Ankara.

Wang, H. F. ve Fu, C. C. (1997), “A Generalization of Fuzzy Goal Programming with Preemptive Structure", Computer and Operations Research, 24 (9): 819-828.

Yang, T., James, P. I. ve Kim, H. J. (1991). "FuzzyProgramming With Nonlinear Membership Functions: Piecewise LinearApproximation”, Fuzzy Sets And Systems, 41 (1): 39-53.

Zadeh, L.A. (1965), “Fuzzy Sets”, Information and Control, 8: 338-353. 